CAMINHOS E AUSÊNC NO PATRIMC DA SAÚD
BELÉM, 


\section{CAMINHOS E AUSÊNCIAS NO PATRIMÔNIO DA SAÚDE EM BELÉM, PARÁ}

\section{Y B E L L E S A L V A D O R M R A N D A}

UNIVERSIDADE FEDERAL DO PARÁ, BRASIL

\section{J A N E F E L I P E B E L T R Ã O}

UNIVERSIDADE FEDERAL DO PARÁ, BRASIL

\section{MÁ R C I O C O U T O H E N R I QU E}

UNIVERSIDADE FEDERAL DO PARÁ, BRASIL 


\title{
CAMINHOS E AUSÊNCIAS NO PATRIMÔNIO DA SAÚDE EM BELÉM, PARÁ
}

\section{Resumo}

Esse artigo apresenta os resultados de inventário realizado sobre a trajetória histórica das instituições de saúde na cidade de Belém, levando em conta sua arquitetura e as mudanças de função que sofreram ao longo do tempo. Essas mudanças estão impressas nas próprias edificações e na memória da população belemense, bem como nos apagamentos decorrentes das demolições de edifícios da saúde. A documentação resultante inclui documentos institucionais, fotografias antigas e atuais, desenhos arquitetônicos e entrevistas, os quais configuram um acervo inexplorado para a compreensão do cuidado com a saúde no Norte do Brasil. A recomposição das trajetórias de implantação e deslocamento das instituições estudadas contribui para a compreensão do processo de expansão urbana, com ocupação de áreas alagadas (decorrente da implantação dos hospícios) e áreas de terra firme, vetor de expansão priorizado pelas políticas higienistas.

Palavras-chave: Patrimônio da saúde, memória, Belém.

\section{PATHS AND ABSENCES IN THE HEALTH HERITAGE OF BELÉM, PARÁ}

\begin{abstract}
This article presents the results of an inventory on the historical trajectory of health institutions in the city of Belem, taking into account its architecture and the role changes that have suffered over time. These changes are imprinted both on the buildings and the memories of the Belem population, as well as in the absences resulted from the demolitions. The resulting documentation includes institutional documents, old and current photographs, architectural drawings and interviews, which constitute a collection untapped for understanding health care in northern Brazil. The reconstruction of the trajectories of deployment and movement of the institutions studied contributes to the understanding of the process of urban expansion, with occupancy of wetlands (due to the implementation of hospices) and land areas, as prioritized by hygienists policies.

Key-words: Health heritage, memory, Belém.
\end{abstract}




\section{CHEMINS ET ABSENCES DANS LE PATRIMOINE DE LA SANTÉ À BELÉM, PARÁ}

\section{Résumé}

Cet article présente les résultats de l'inventaire qui s'est tenue sur la trajectoire historique des institutions de la santé dans la ville de Belém, compte tenu de son architecture et les changements qui ont souffert au fil du temps. Ces changements sont imprimés dans leurs propres bâtiments et à la mémoire de la population de Belém, ainsi que les destructions résultant de la démolition des bâtiments de la santé. La documentation qui en résulte comprend les documents institutionnels, vieilles et modernes photos, dessins architecturales et interviews, qui constituent une collection inexploitée pour la compréhension des soins de santé dans le nord du Brésil. La recomposition des trajectoires de déploiement et de décalage des établissements étudiés contribue à la compréhension du processus d'étalement urbain, avec l'occupation des terres humides (résultant du déploiement des hospices) et les zones arides, vecteur expansioniste priorisée par la politique hygiéniste.

Mots-clé: Patrimoine e la santé, memoire, Belém

Endereço da primeira autora para correspondência: Avenida Senador Lemos, $n^{\circ}$ 54, apto 404 Umarizal, CEP 66050-000, Belém/PA, Brasil. E-mail: cybelle@ufpa.br 


\section{NOS CAMINHOS DO PATRIMÔNIO DA SAÚDE}

Para contar a história da construção do patrimônio da saúde em Belém, é preciso fazer o inventário dos achados e perdidos pelo caminho... perdidos que foram grandes descobertas e achados repletos de ruínas.

A primeira fase dos trabalhos relativos ao Projeto Rede Brasil - Inventário Nacional do Patrimônio Cultural da Saúde: bens edificados $e$ acervos na cidade de Belém, $\mathrm{PA}^{1}$ ocorreu entre setembro de 2009 e fevereiro de 2010, sendo a pesquisa concluída em agosto de 2011. Tudo começou com o convite feito à professora Jane Beltrão, experiente pesquisadora nestas searas da saúde e do patrimônio, ou vice-versa. Depois, Cybelle Salvador Miranda foi incluída nesta tarefa por ser arquiteta antropóloga, arrebatando também a arquiteta Carla Albuquerque e a designer graduanda em Arquitetura Laura Costa. Logo em seguida foi convidado o historiador antropólogo Márcio Couto Henrique, detentor de vasto conhecimento sobre a Santa Casa de Misericórdia do Pará. Assim, munidos de muita determinação, seguimos a campo.

Iniciou-se com uma relação das principais instituições a serem investigadas, segundo a antiguidade e a relevância para a narrativa sobre a assistência à saúde em Belém. Como o período inicialmente proposto para a execução da pesquisa fora de seis meses, as coordenadoras do projeto optaram por dedicar-se ao estudo de 13 instituições, já que, após o envio do Relatório Parcial, o coordenador geral do projeto Professor Renato Gama-Rosa Costa solicitou que se abrangesse um número maior de instituições, reforçando que o intuito do trabalho seria o de mapear quantitativamente as edificações e acervos presentes em cada capital (Quadro 1). Com a ampliação do período de atividades por mais 6 meses, o pesquisador Márcio Couto sugeriu a inclusão de três instituições inexistes atualmente, mas de grande relevância para a compreensão da história do cuidado a saúde na cidade: o Hospital do Senhor Bom Jesus dos Pobres, o Hospital Real e o Hospício dos Lázaros. Destes, apenas a edificação do Hospital Real permanece, sendo hoje ocupada pelo Espaço Cultural Casa das 11 janelas. Três hospitais particulares de existência mais recente também foram elencados, bem como instituições públicas que fazem parte do patrimônio material e imaterial da saúde em Belém, destacando-se por suas edificações de linhas modernas e contemporâneas, como o Conjunto de edifícios do antigo INSS na Avenida Presidente Vargas e o Hospital de Clínicas Gaspar Vianna. O curto período disponibilizado para o Inventário não foi obstáculo para nossa curiosidade, sendo que o tema deslizou para as conexões e relações pessoais dos pesquisadores envolvidos, representando oportunidade de trazer à luz memórias de personagens até então obscurecidos na história da saúde em Belém.

As principais barreiras impostas ao trabalho foram a burocracia vigente nas instituições públicas, bem como a ausência de acervo organizado. A tal ponto que, em algumas edificações, precisamos empregar métodos não 
ortodoxos para a obtenção de imagens (inclusive o recurso a frestas em portas e fechaduras). Papéis que se perdiam, eram extraviados, ou instituições que simplesmente negavam o acesso ou o registro de imagens, alegando "questões de segurança" foram situações frequentes durante a coleta de dados.

Os resultados, porém, recompensaram os esforços: das instituições investigadas produziu-se histórico dos principais eventos, ilustrado por iconografia antiga e recente. Arquitetonicamente, fez-se a descrição das edificações, algumas não mais existentes, e obtiveram-se os desenhos em planta de algumas delas, material disponível para futuras incursões pelo tema. Além da simples coletânea de fichas, foi observada a relação entre a implantação dos hospitais e a expansão da cidade, proporcionando a setorização daqueles em núcleos, denominados Núcleo Pioneiro, Núcleo Santa Casa e Núcleo de Expansão (Figura 1, Quadro 2). Ao realizar o estudo, percebeu-se que a localização dos hospitais e asilos repercutiu na ampliação da área urbana da cidade, como no caso dos Hospitais de Isolamento, que conduziram a ocupação das áreas baixas da cidade correspondentes ao Bairro do Guamá, parte do denominado Núcleo de Expansão. Por outro lado, a transferência do Hospital da Santa Casa, que veio a ocupar o prédio do Bom Jesus no Largo da Sé no início do século XIX, para a atual sede no bairro do Umarizal, também contribuiu para a aglutinação de instituições de saúde no entorno, a qual denominados Núcleo Santa Casa.
O "Núcleo Pioneiro" compreende a área inicial de colonização de Belém, estendendo-se pelos bairros da Cidade Velha e Batista Campos. Neste espaço temos o primeiro nosocômio do Pará: o Hospital Real, bem como o primeiro hospital construído em alvenaria, o "Bom Jesus dos Pobres enfermos". Esse núcleo foi espraiando-se em razão do crescimento urbano da cidade e em razão das políticas urbanas higienistas que preconizaram o afastamento de determinadas doenças do centro de Belém, configurando-se o "Núcleo de Expansão". Nele, encontramos o Hospital dos Lázaros do Tucunduba, o Hospício de Alienados do Tucunduba, o Hospital Juliano Moreira e os Hospitais de Isolamento.

Ao deslocar-se de suas instalações à Praça D. Frei Caetano Brandão, a Santa Casa de Misericórdia configurou um núcleo próprio, aqui chamado Núcleo Santa Casa, que compreende o entorno do Largo de Santa Luzia, onde se encontra o Hospital da Santa Casa de Misericórdia, maior referência em saúde na cidade de Belém, tanto por sua história quanto pelos serviços que dispõe (Beltrão et al 2011).

Sem dúvida, a demolição do antigo Hospital da Caridade, no núcleo pioneiro da cidade, e o desaparecimento do Hospício de Alienados são representativos de uma memória que se quer seletiva. Assim, discutir memória e patrimônio no Pará a partir das instituições de atenção a saúde reveste-se de importância, como emblema de um fluxo de permanências e apagamentos na memória da cidade de Belém. 


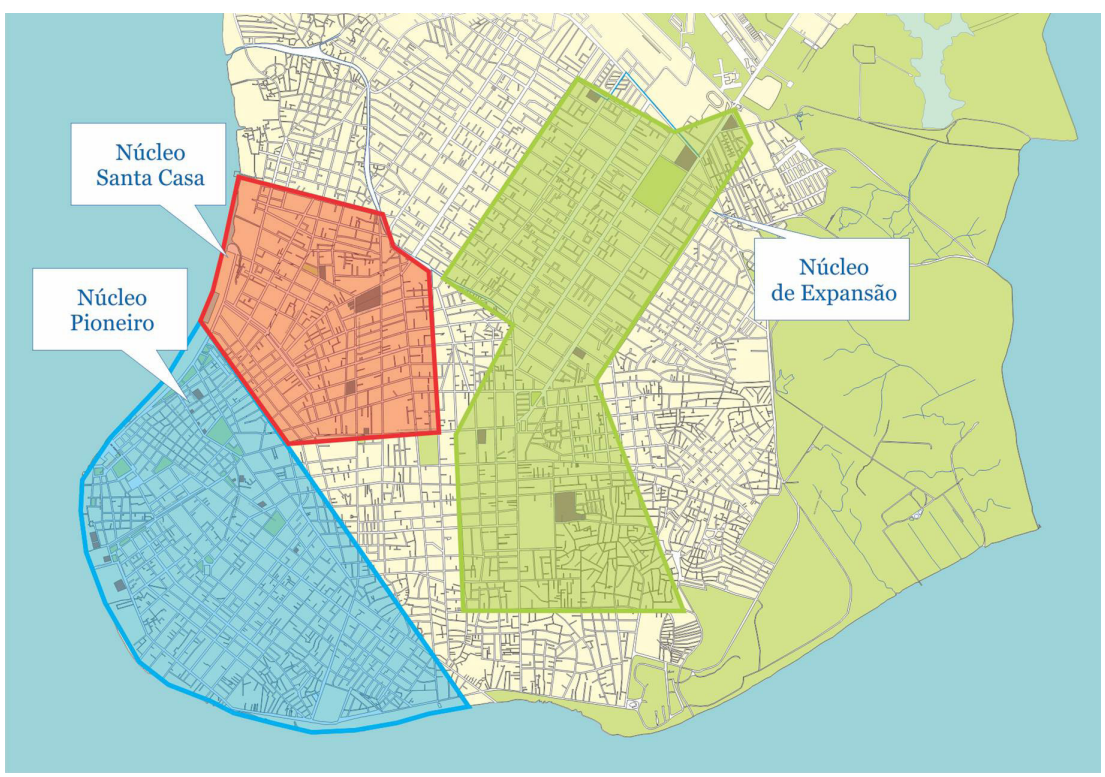

Figura 1 - Mapa com delimitação dosnúcleos da saúde. Fonte: Laura Costa, 2011.

Quadro 1

Relação das Instituições de saúde selecionadas para pesquisa

\begin{tabular}{|l|l|}
\hline $\begin{array}{l}\text { Instituições selecionadas } \\
\text { inicialmente }\end{array}$ & $\begin{array}{l}\text { Instituições adicionadas } \\
\text { posteriormente }\end{array}$ \\
\hline Fundação Santa Casa de Misericórdia do Pará & Hospital do Bom Jesus dos Pobres Enfermos \\
\hline $\begin{array}{l}\text { Hospital Dom Luis I da Beneficente } \\
\text { Portuguesa }\end{array}$ & Hospital Real \\
\hline Hospital da Ordem Terceira & Hospício dos Lázaros \\
\hline Hospital Ophir Loyola & Hospital Nossa Senhora de Guadalupe \\
\hline Hospital Naval de Belém & Maternidade do Povo \\
\hline Instituto de Ciências da Saúde da UFPA & Clínica dos Acidentados \\
\hline Centro de Saúde I & Núcleo de Medicina Tropical \\
\hline Hospital Universitário Barros Barreto & Instituto Nacional de Seguridade Social INSS \\
\hline Hospital da Aeronáutica & Fundação Centro de Hematologia e \\
& Hemoterapia do Pará \\
\hline Hospital do Exército & Hospital de Clínicas Gaspar Vianna \\
\hline Hospital Psiquiátrico Juliano Moreira & \\
\hline Instituto Evandro Chagas & \\
\hline Pronto Socorro Municipal & \\
\hline
\end{tabular}


Quadro 2

Instituições quanto à localização nos Núcleos

\begin{tabular}{|l|l|l|}
\hline Núcleo Pioneiro & Núcleo Santa Casa & Núcleo de Expansão \\
\hline Hospital Real & $\begin{array}{l}\text { Fundação Santa Casa de } \\
\text { Misericórdia do Pará }\end{array}$ & Hospício dos Lázaros \\
\hline $\begin{array}{l}\text { Hospital do Bom Jesus dos } \\
\text { Pobres Enfermos }\end{array}$ & $\begin{array}{l}\text { Hospital Dom Luis I da } \\
\text { Beneficente Portuguesa }\end{array}$ & $\begin{array}{l}\text { Hospital Universitário Barros } \\
\text { Barreto }\end{array}$ \\
\hline Hospital Naval de Belém & $\begin{array}{l}\text { Instituto de Ciências da } \\
\text { Saúde da UFPA }\end{array}$ & Hospital Ophir Loyola \\
\hline Hospital da Ordem Terceira & Núcleo de Medicina Tropical & Instituto Evandro Chagas \\
\hline $\begin{array}{l}\text { Instituto Nacional de Se- } \\
\text { guridade Social INSS }\end{array}$ & Hospital do Exército & $\begin{array}{l}\text { Hospital de Clínicas Gaspar } \\
\text { Vianna }\end{array}$ \\
\hline $\begin{array}{l}\text { Fundação Centro de Hemato- } \\
\text { logia e Hemoterapia do Pará }\end{array}$ & Pronto Socorro Municipal & $\begin{array}{l}\text { Hospital Psiquiátrico } \\
\text { Juliano Moreira }\end{array}$ \\
\hline Centro de Saúde I & Clínica dos Acidentados & Hospital da Aeronáutica \\
\hline Maternidade do Povo & & \\
\hline $\begin{array}{l}\text { Hospital Nossa Senhora } \\
\text { de Guadalupe }\end{array}$ & & \\
\hline
\end{tabular}

\section{O NÚCLEO PIONEIRO}

O termo "núcleo pioneiro" refere-se à localização das instituições de saúde na área inicial de colonização de Belém, sendo a primeira delas o Hospital Real. Instalado inicialmente no Forte do Presépio, em 1760 o Governador Melo e Castro propôs sua transferência para o convento de São Boaventura; mas, tendo este assumido a função de arsenal, a construção precisou ser adiada até 1768 , quando o Governador Ataíde Teive comprou as residências de Domingos da Costa Bacelar para tal propósito. $\mathrm{O}$ projeto de adaptação coube a Antonio Landi, da Comissão Demarcadora de Limites, e o hospital passou a atender doentes provindos das fragatas. ${ }^{2}$

Durante o século XX, o prédio tornouse Quartel do Exército, sendo alterado interna e externamente. Foi tombado pelo Instituto do Patrimônio Histórico e Artístico Nacional (IPHAN) em 17 de dezembro de 1964 e, no início dos anos 2002, com a conclusão das obras do Projeto Feliz Lusitânia, o edifício voltou a seguir os desenhos de Landi, tornando-se o Centro Cultural "Casa das Onze Janelas” (Secult 2006).

O edifício possui planta em "L", composto por um retângulo maior paralelo ao rio, com fachada principal voltada ao Largo da Sé, com outro retângulo menor adossado do lado poente. A fachada principal possui dois pavimentos; no $1^{\circ}$ pavimento o portal central é acompanhado por cinco janelas de cada lado, e no segundo pavimento possui 11 portas-janela com gradis em ferro. A fachada voltada para o rio compõe-se de loggias ao gosto italiano nos dois pisos (Figura 2). 


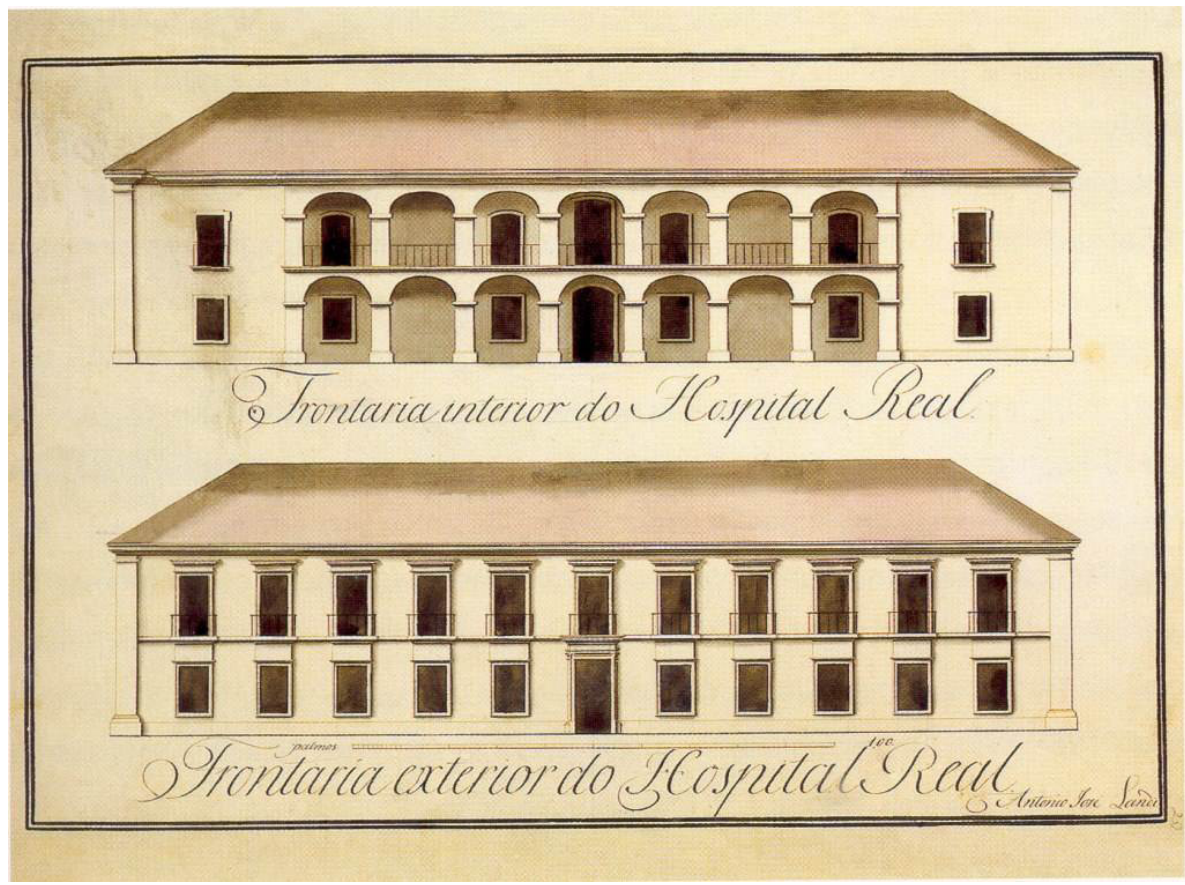

Figura 2 - Projeto de Landi para o Hospital Real. Fonte: Amazônia Felsínea (1999: 213).

Ao lado dessa edificação, no local onde atualmente existe um chafariz, funcionava o Hospital do Bom Jesus dos Pobres Enfermos, cuja construção, em 1785, só foi possível graças às doações pedidas por Frei Caetano Brandão para acolher os pobres enfermos da cidade, além de ter sido o local onde foram feitos os primeiros atendimentos a doentes mentais no Pará. Inaugurado em 1787, construído e administrado pela Confraria da Caridade, foi incorporado aos bens da Santa Casa de Misericórdia em 1807, mas suas atividades encerraram-se em 1900. Em 1957, foi desapropriado e entregue ao Ministério de Guerra, que o utilizava como Estabelecimento de Subsistência.Tombado pela então Diretoria do Patrimônio Histórico e Artístico Nacional em 1964, foi demolido em 1978, e com ele se foi o docu- mento vivo da primeira instituição hospitalar em alvenaria no Estado (Beltrão et al 2011).

Baena (2004) relata que o prédio apresentava três janelas entre duas portas no primeiro pavimento, cinco janelas de sacada e balcões de ferro no segundo e duas de peitoril no terceiro. A planta apresentava dois quadrados ligados por um paralelogramo. Dentre os ambientes, destacavam-se a enfermaria, também chamada de "casa grande", que possuía uma coxia com altar de retábulo dourado, onde aconteciam as missas (Figura 3).

Ainda no núcleo pioneiro, seguindo pela Rua Dr. Assis, passando pelo Arsenal de Marinha, encontra-se o Hospital Naval, no limite entre os bairros Jurunas e Cidade Velha (Beltrão 


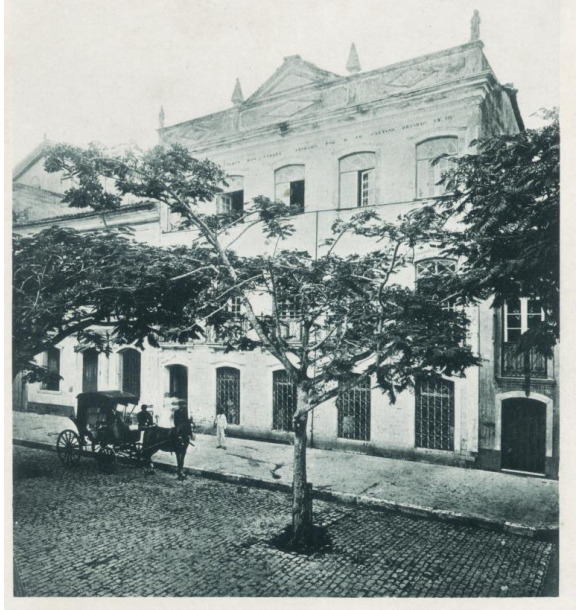

Figura 3 - Hospital Bom Jesus dos Pobres. Fonte: Vianna (1992: 80-81).

et al 2011). Atualmente, a instituição tem por objetivo o atendimento por meio do Sistema de Saúde da Marinha (SSM), bem como a supervisão de atividades de assistência médico-social às comunidades ribeirinhas na Amazônia ocidental e oriental. O Hospital Naval de Belém, também conhecido como Hospital da Marinha ou do Arsenal, localizado na Rua do Arsenal, no 200, em frente à Praça Carneiro da Rocha, também conhecida como Praça do Arsenal, foi construído a partir de 1958; entre os construtores destaca-se o Engenheiro Alfredo Boneff. ${ }^{3}$

A criação da casa de saúde ocorreu na década de 1950, instituída pelo Decreto $\mathrm{N}^{\circ}$. 44.193, de 31 de dezembro de 1958. Antes, era o prédio dos Sub-Oficiais e Primeiros Sargentos do Comando de $4^{\circ}$ Distrito Naval. As reformas e ampliações efetuadas para a adaptação do edifício para prédio hospitalar foram executadas pelo Escritório Técnico-Administrativo de Belém (ETA) através do engenheiro Otávio Pires.

Em 1965, foi criado o pavilhão posterior, local onde hoje funciona a enfermaria do Fundo de Saúde da Marinha (FUSMA). Em 1971, foram iniciadas obras que conferiram ao nosocômio o aspecto que possui hoje. Em 4 de janeiro de 1972 foi inaugurado o Pavilhão Administrativo.

O prédio encontra-se edificado em dois pavimentos em forma de $\mathrm{U}$, com jardim interno. A implantação no terreno apresenta recuo frontal, lateral e fundo, este último margeado pelo rio Guamá. A área total construída é de aproximadamente $7.980 \mathrm{~m}^{2}$, com $105 \mathrm{~m}$ de frente por $76 \mathrm{~m}$ de fundo. $\mathrm{O}$ jardim central dá acesso ao primeiro pavilhão, ala localizada à esquerda do prédio e onde estão instalados os serviços administrativos pertinentes ao Hospital. O segundo pavilhão está situado na ala central do prédio, é destinado aos serviços emergenciais. $\mathrm{O}$ terceiro pavilhão está na ala à direita do prédio sendo destinados aos serviços ambulatoriais (Beltrão et al 2011)(Figura 4).

Acompanhando o crescimento da cidade rumo a seu segundo sítio de ocupação, no bairro da Campina, foi edificado o Hospital da Ordem Terceira de São Francisco, localizado na Travessa Frei Gil de Vila Nova (antiga Travessa Santo Antônio), no 59, construído a partir de 1864 pela Venerável Ordem Terceira de São Francisco.

A princípio, a Ordem Franciscana atendia seus enfermos em uma pequena barra- 


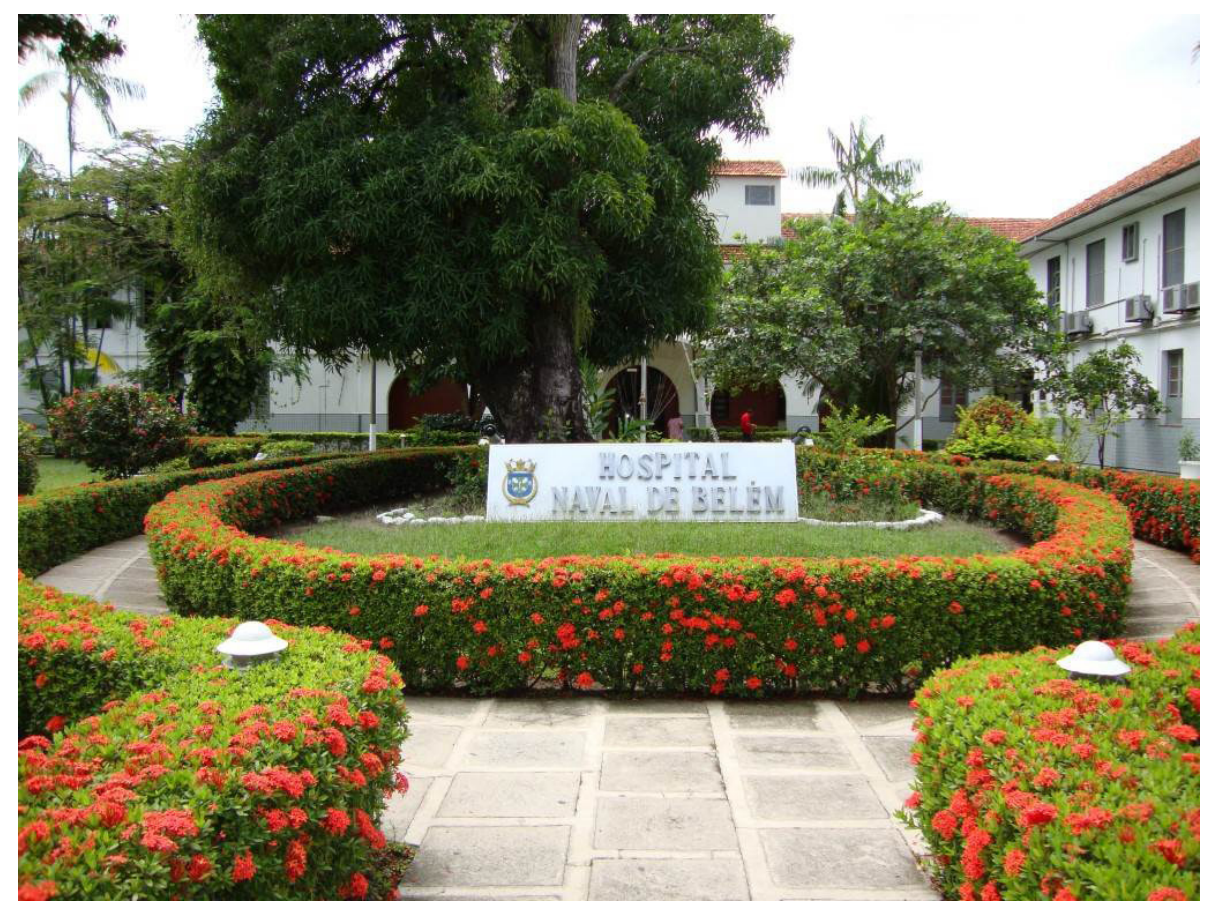

Figura 4 - Acesso principal Hospital Naval de Belém. Foto: Carla Albuquerque (2010).

ca de palha, no litoral da Baía do Guajará. No entanto, em 1694, os franciscanos do Convento de Santo Antônio cederam aos Irmãos Terceiros um terreno para a construção de uma capela. Contígua à ela foi construída em 1864 a enfermaria que originaria o futuro hospital, edificada em três pavimentos, com $13 \mathrm{~m}$ de largura por 4,5 $\mathrm{m}$ de fundos. Já em 1867 o novo Hospital foi inaugurado, contendo três enfermarias: São Roque, Santa Clara e Santo Ivo. ${ }^{4}$

O hospital sofreu diversas modificações através dos anos, no entanto, ainda hoje preserva sua função de hospital geral. A construção foi implantada no alinhamento frontal e lateral do terreno, edificado em três pavimentos, encontrandose a volumetria original da edificação preservada. A edificação apresentava estilo neoclássico, com fachada azulejada, platibanda balaustrada, vãos de porta e janela em arco pleno no primeiro e segundo pavimentos e arcos trilobados no terceiro (Figura 5).

Hoje essas características arquitetônicas se perderam, já que as esquadrias de madeira foram substituídas por balancins em ferro, a platibanda e os detalhes arquitetônicos foram substituídos por marcações horizontais e verticais por toda a fachada, em padrão "modernizante". Destacam-se como remanescentes somente a capela e o hall de entrada do hospital.

Próximo ao Hospital da Ordem Terceira, na Avenida Presidente Vargas, está um dos prédios do antigo Instituto Nacional de Seguridade Social (INSS), 


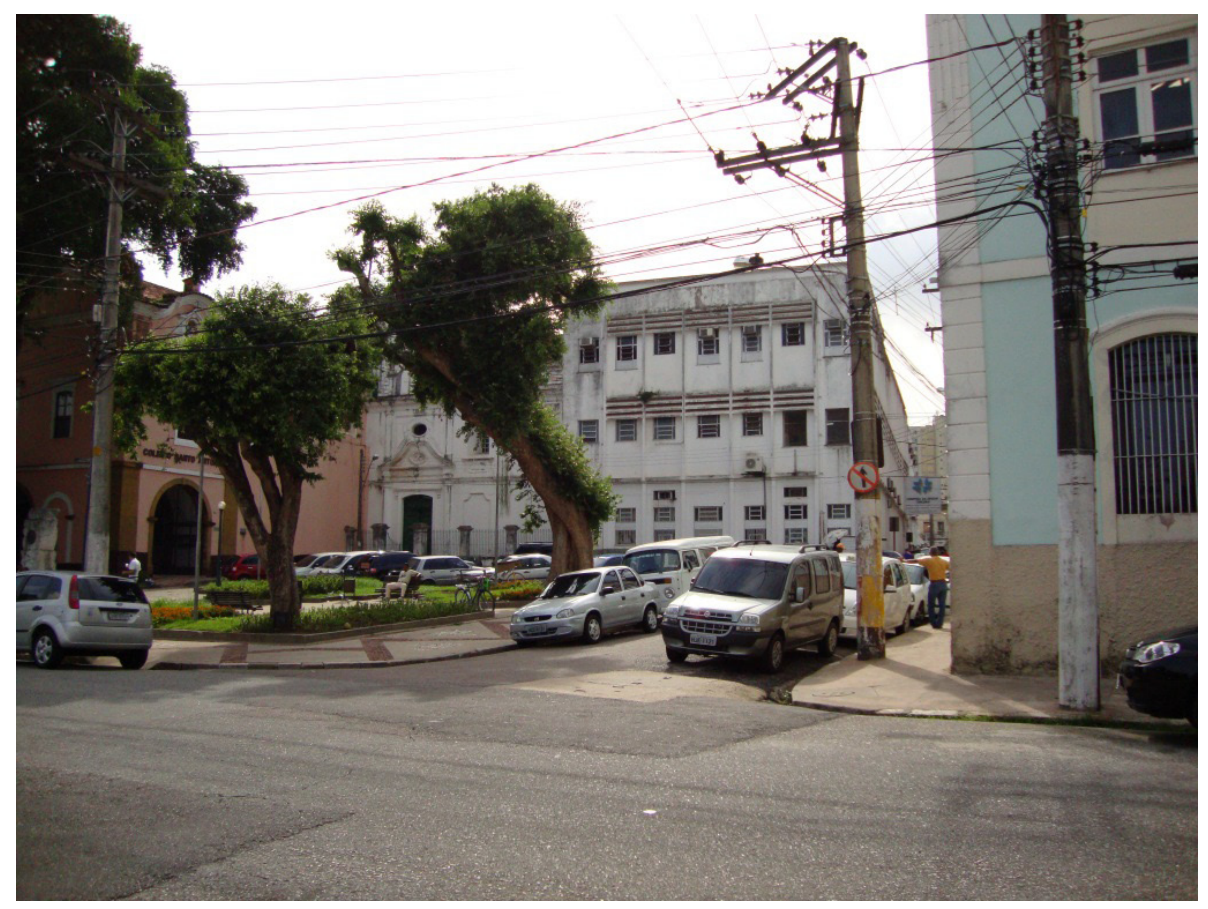

Figura 5 - Hospital e Capela da Ordem Terceira. Foto: Carla Albuquerque (2009).

onde ainda se vê a denominação anterior a esta: INAMPS (Instituto Nacional de Assistência Médica da Previdência Social), edificação construída em meados dos anos 1950/60, cujo construtor foi Edmar Porto Penna de Carvalho.

Antes da criação do Sistema Único de Saúde (SUS), a assistência médica estava a cargo do INAMPS, restrita aos empregados que contribuíssem com a previdência social. O INAMPS foi criado pelo regime civil-militar em 1974 pelo desmembramento do Instituto Nacional de Previdência Social (INPS), que tinha por finalidade prestar atendimento médico aos contribuintes. Hoje assumiu a denominação de Instituto Nacional de Seguridade Social (INSS) (Brasil 2006).
O patrimônio do INSS é composto por diversas edificações, porém destaca-se o prédio do INAMPS situado na Travessa Manoel Barata, esquina com a Avenida Presidente Vargas, no Centro Comercial de Belém (Figura 6). As edificações onde funcionaram os Institutos de Saúde guardam padrões modernistas, porém de épocas diferentes. Embora a edificação ocupe o alinhamento, apresenta linhas modernistas com emprego de janelas recuadas e brises horizontais em concreto, em clara referência ao prédio modelo do modernismo brasileiro, sede do Ministério da Educação e Saúde no Rio de Janeiro.

Fundado em 1961 e construído entre os anos de 1967 e 1977, o Hospital Nossa Senhora de Guadalupe localizase no bairro de Batista Campos, na Rua 
Arcipreste Manoel Teodoro, $n^{\circ} 734$. De propriedade da Sociedade das Irmãs Adoradoras do Sangue de Cristo - ordem criada na cidade de Acuto, na Itália, em 1834, por Santa Maria de Mattias -, teve projeto de autoria de Francisco Bolonha, e execução das obras por parte de Nicholas Chase (Beltrão et al 2011).

Sua primeira sede localizava-se na Avenida Assis de Vasconcelos, no 757. A “casa azul", como era chamada, foi adquirida em 1962 e entregue à congregação em 8 de novembro do mesmo ano. Dois anos depois tiveram início alguns trabalhos de reforma deste prédio. No entanto, após a inauguração do atual hospital, em $1^{\circ}$ de fevereiro do ano seguinte, a "casa azul" passou a residência de algumas irmãs da congregação. Atualmente funciona no local a Clínica de Crianças Pio XII.

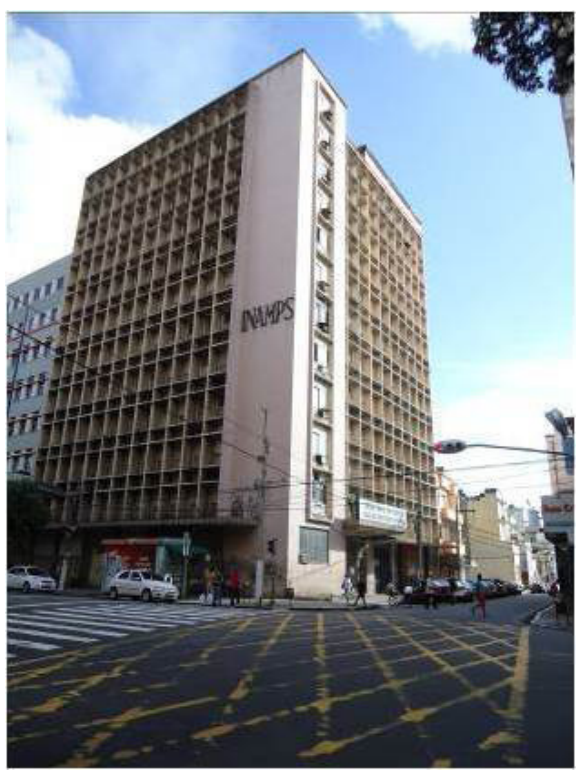

Figura 6 - Prédio INAMPS. Foto: Laura Costa (2011).
A “casa azul" é caracterizada pelo estilo protomoderno, expresso em linhas art decò. A simplicidade da volumetria contrasta com o gradil com arabescos em ferro do portão principal e do muro que protege a edificação. Já o imóvel atual situa-se em terreno mais amplo, constituído de um bloco principal e de um anexo. A construção apresenta recuos laterais e frontais, sendo este último bem mais acentuado na entrada do hospital, servindo de estacionamento. A planta do Hospital Guadalupe é linear, acompanhando a volumetria retangular da instituição. Externamente, por ser uma construção em estilo moderno, optou-se por deixar o acabamento em concreto aparente, cuja textura é interrompida pela fachada principal em pedras irregulares de tons de cinza e terrosos (Figura 7).

O bloco anexo, onde funcionam as clínicas, adota linguagem pós-moderna. A planta segue o mesmo padrão da primeira construção, embora em escala menor, comunicando-se com o edifício principal por passagem metálica situada no primeiro pavimento.

A Maternidade do Povo foi construída em 1958 pelo engenheiro Nicholas Chase, o mesmo construtor do Hospital Nossa Senhora da Guadalupe. Localizada no bairro da Campina, na Travessa Ferreira Cantão, n ${ }^{\circ} 483$, a maternidade surgiu através da iniciativa de um grupo de médicos liderados pelo Dr. Paulo Mota Castro. O primeiro imóvel ocupado pela Maternidade localizava-se na Travessa Padre Prudêncio, local onde, hoje, funciona a Secretaria de Administração do Es- 


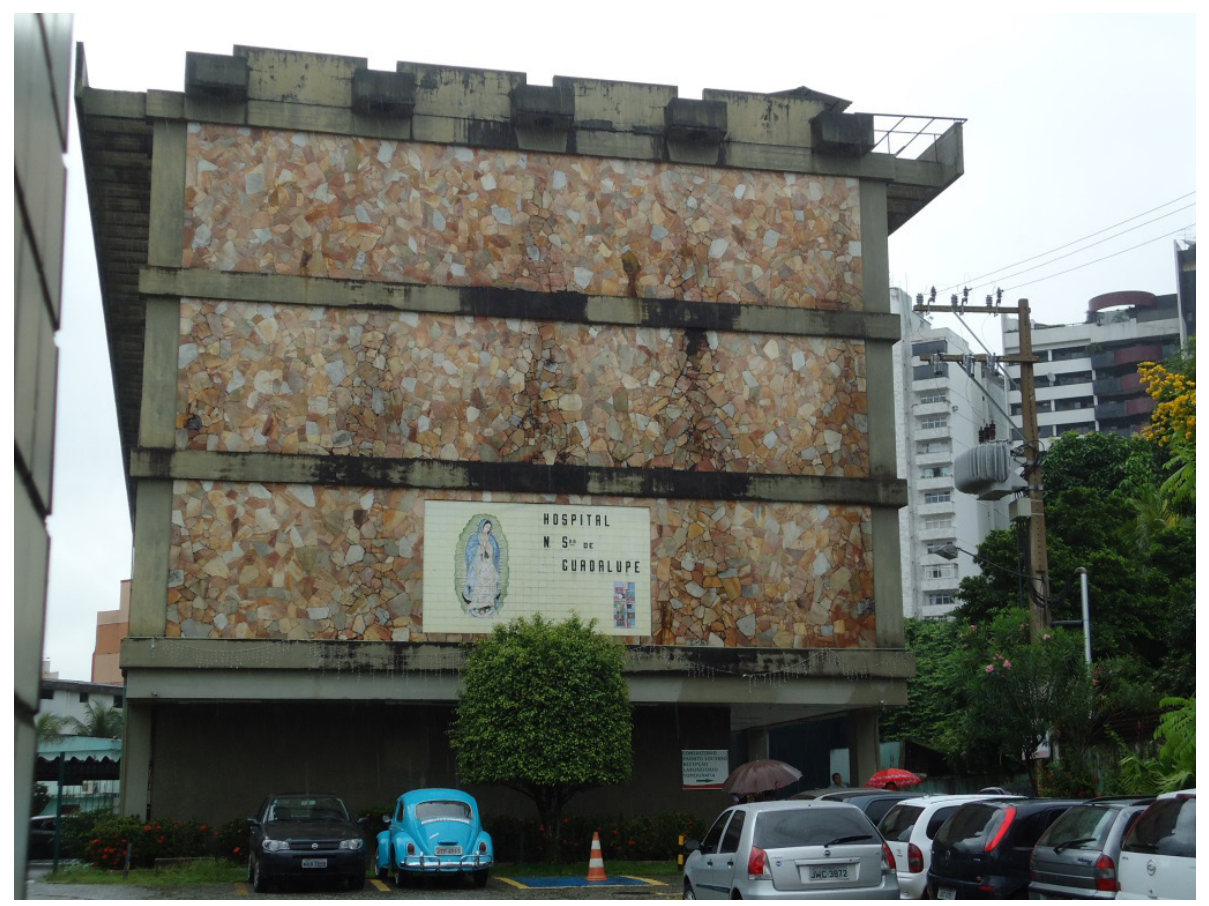

Figura 7 - Fachada Hospital Guadalupe. Foto: Laura Costa (2011).

tado do Pará (SEAD), imóvel este cedido pelo Estado. Posteriormente, o Governo do Estado, na gestão de Aurélio do Carmo doou, em 1965, o terreno onde foi edificada a sede da Maternidade na Travessa Ferreira Cantão. O novo endereço permitiu a construção de edificação com padrões de qualidade para atendimento hospitalar conforme as exigências da época (Beltrão et al 2011).

Edificada no alinhamento do terreno, em quatro pavimentos com estrutura em concreto armado, alvenaria de tijolo e vãos em esquadrias de alumínio e vidro, em alguns casos há a utilização de vidro temperado transparente liso. A fachada possui acabamento em revestimento cerâmico dimensões $10 \mathrm{x}$ $10 \mathrm{~cm}$, nas cores bege e azul, sendo o bege usado nos panos de parede e o azul, nas marcações. No primeiro pavimento funcionam o bloco cirúrgico, a central de material e esterilização (CME), posto de enfermagem, repouso médico, e 23 leitos disponibilizados para enfermarias e apartamentos. No segundo pavimento estão instalados 16 apartamentos, uma suíte master composta por amplo quarto, sala de estar com monitor capaz de repetir as cenas do parto ou qualquer outro vídeo que o paciente desejar e um banheiro; a UTI neo-natal, berçário e o isolamento totalizam 20 leitos. O terceiro pavimento, em construção, está projetado para receber 16 apartamentos (Figura 8).

Próximo dali está o Centro de Saúde $n^{\circ} 1$, vinculado à Secretaria de Estado de Saúde Pública do Pará (SESPA). O Centro I, localizado na Travessa Presi- 
dente Pernambuco, $\mathrm{n}^{\circ} 489$, funcionou até os anos 1970 como centro de referência para consultas, exames, vacinas, entre outros serviços relacionados. Com a mudança na oferta dos serviços do setor privado de saúde, as atividades do Centro foram encerradas. A Secretaria de Saúde, que possuía alguns departamentos funcionando na área contígua à Instituição, passou a ocupar o espaço de forma integral.

$\mathrm{O}$ prédio, hoje, encontra-se muito modificado. A construção é composta de cinco blocos de alvenaria (sendo dois destes com térreo e pavimento superior), inseridos em terreno de formato poligonal. O bloco principal apresenta recuos laterais e frontais, e os demais se encontram nos limites do terreno. Em termos de fachada, a construção apre- senta regularidade através de aberturas retangulares: as portas e janelas apresentam esquadrias em madeira, presentes em todos os blocos, embora seja possível observar o contraste com alguns balancins em alumínio. $\mathrm{O}$ revestimento externo é chapiscado, o que confere aparência rústica ao prédio. A cobertura é de águas combinadas, revestida de telha cerâmica, com beiral estreito (Beltrão et al 2011).

A planta do prédio apresenta configuração irregular acentuada, provavelmente como resultado de sua ampliação ao longo dos anos. No andar térreo, podem ser encontrados os departamentos de Controle de Epidemias, de Doenças, de Atenção à Saúde, Assistência Farmacêutica, Controle de Hanseníase, Vigilância Sanitária e outros departa-

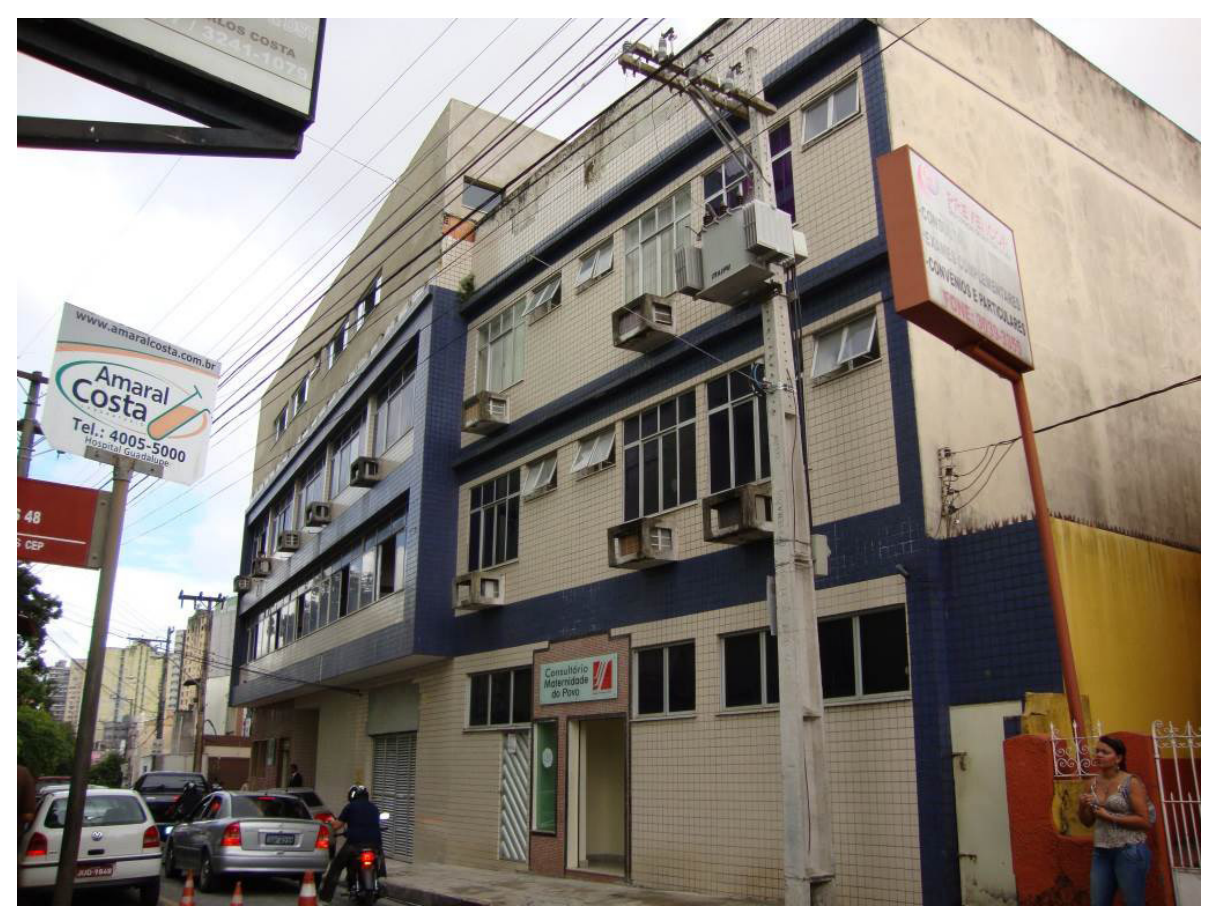

Figura 8 - Prédio maternidade do povo. Foto: Carla Albuquerque (2010). 
mentos relacionados à administração da instituição, sendo alguns deles situados em anexos construídos ao fundo do terreno. No segundo pavimento, há predominância de espaços destinados às funções administrativas.

Pouco mais além, no bairro Batista Campos, encontra-se a Fundação Centro de Hematologia e Hemoterapia do Pará (HEMOPA). Criada em 1978, por meio do decreto Lei no 10.741, denominavase Fundação Centro Regional de Hemoterapia do Pará (FUNEPA) e tinha como objetivo estimular a doação de sangue. Inicialmente localizada na Avenida Generalíssimo Deodoro, 973, seguia o modelo francês - voluntariado e anonimato. $^{5}$

A fundação foi criada no contexto do Programa Nacional de Sangue do Governo Federal, quando foi iniciada campanha para criação de Hemocentros Estaduais, a partir da década de 1970, com o objetivo de estimular a prática da doação de sangue pela comunidade e com finalidade social, além de organizar a demanda nacional de sangue.

Em razão do aumento da demanda por coleta de sangue, ocasionando a falta de espaço para realização dos trabalhos no edifício, foi adquirida sede mais ampla que atendesse às necessidades funcionais, localizada à Avenida Magalhães Barata, no 1136. Entretanto, o avanço da medicina no tratamento e manuseio do sangue exigiu espaço adequado aos serviços oferecidos, obrigando a transferência para outro imóvel. Foi comprado terreno localizado à Travessa Padre Eutíquio, no 2109 , que possibilitou construir prédio que estivesse de acordo com as normas impostas pela Agência Nacional de Vigilância Sanitária (ANVISA).

O prédio atual foi inaugurado em 29 de março de 1994, com $4.000 \mathrm{~m}^{2}$ de área construída. Tendo como proprietário a Secretaria de Estado de Saúde Pública do Pará (SESPA), seu projeto é de autoria do arquiteto Paulo Lima, integrante do Escritório de Arquitetura DPJ. A edificação emprega tipologia moderna, edificada em alvenaria de tijolo cerâmico e estruturada por pilares de concreto. $\mathrm{Na}$ fachada principal, a composição dos brises horizontais e o pano de vidro ajudam a diminuir o consumo de energia gasto pela edificação, além de permitir a visibilidade para o exterior.

À exceção do fundo, as demais implantações foram executadas com afastamento da testada do lote. Constituído por cinco pavimentos, o prédio possui acabamento cerâmico em todas as fachadas, vãos retangulares dispostos de forma simétrica segundo a proposta para cada fachada, com esquadrias em ferro e fechamento em vidro fumé. Platibanda de concreto encobre e arremata a cobertura (Figura 9).

\section{O NÚCLEO SANTA CASA}

A escolha do termo "Santa Casa" para compor este núcleo não foi aleatória, e sim reflexo da influência que esta instituição exerce sobre as demais situadas em seu entorno, bem como do papel desempenhado como protagonista de boa parte das ações voltadas à assistência à saúde pública em Belém desde 


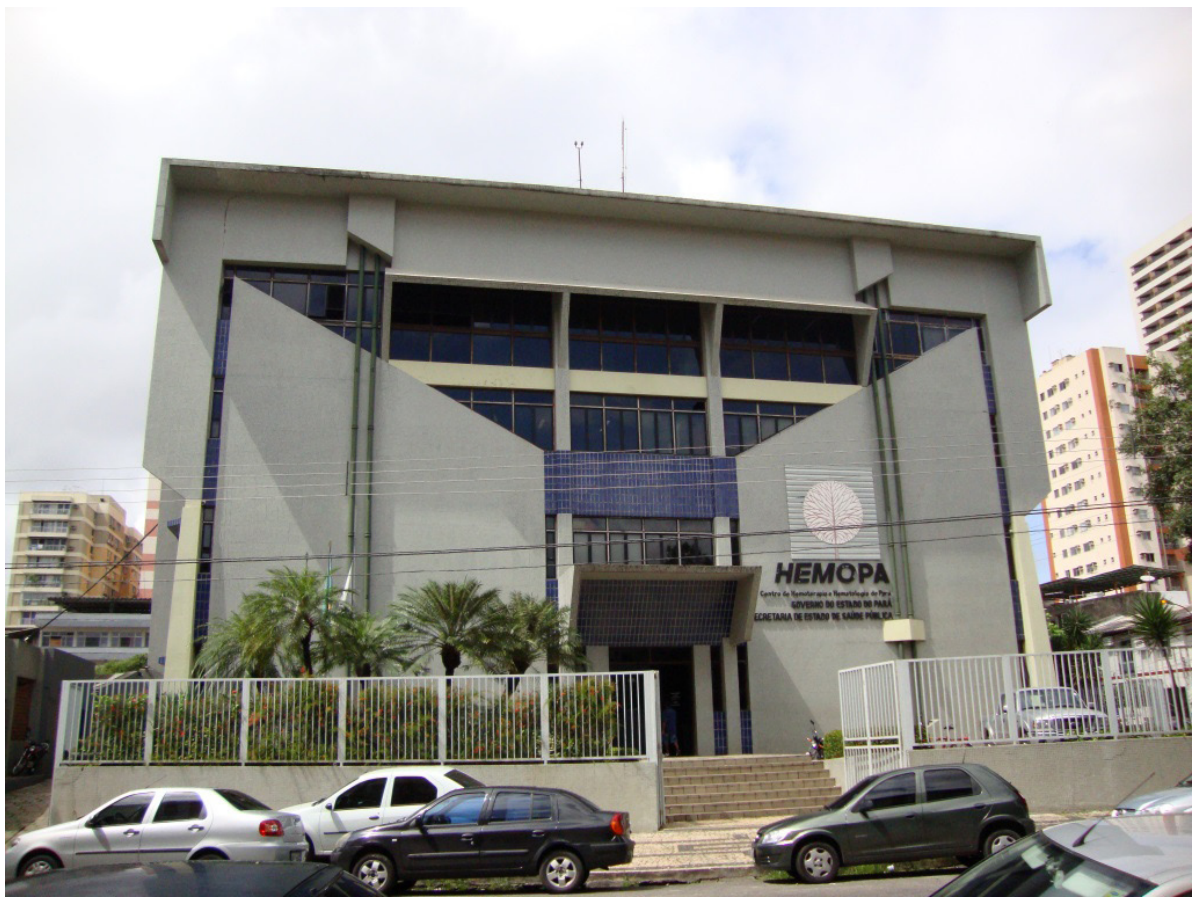

Figura 9 - Fachada HEMOPA. Foto: Carla Albuquerque (2010).

sua fundação, em 1650, ao lado da loja Paris n'América - pequeno edifício com igrejinha ao lado, ambos de taipa (Vianna 1992). Sobrevivendo por muito tempo através de doações e loterias, em anúncios que podem ser encontrados em jornais do século XIX ("O Paraense" e "A Província do Pará”), a Santa Casa foi responsável pela administração do Hospício dos Lázaros, acolheu os doentes da epidemia de febre amarela, em 1850, e conduziu a assistência aos variolosos e coléricos nos hospitais de isolamento.

Marco em sua história, a criação da maternidade em 1914 desencadeou a ampliação de seus serviços à população e, pelo histórico de caridade e serviços públicos, foi considerada modelo no atendimento humanizado à gestan- te e ao recém-nascido pelo Ministério da Saúde (Beltrão et al 2011), embora figure de forma pouco honrosa com certa frequência nos noticiários do Estado, pela carência de infraestrutura e investimentos necessários para atender à crescente demanda por atendimento. Em 1987, a instituição fundou o Museu e Arquivo Histórico da Santa Casa (MAHSC), cujo acervo reúne parte considerável da memória da instituição (Figura 10).

Em 1807, o Hospital Senhor Bom Jesus dos Pobres, com todos os seus bens patrimoniais, foi incorporado à SCMP, onde a Misericórdia paraense funcionou até 1900. Em 1890, a SCMP deixou de ser Irmandade e passou a ser uma Associação Civil de Caridade. Na mesma data, foi lançada a primeira 
pedra do novo Hospital da Caridade, no bairro do Umarizal, com planta do engenheiro Manoel Odorico Nina Ribeiro, onde se deu a inauguração de sua maternidade, em 1914, e a formação do hospital-escola do Estado do Pará, contribuindo para a formação de muitos médicos paraenses. Em 1990, a Associação Civil de Caridade tornouse Fundação Santa Casa de Misericórdia do Pará (FSCMP), financiada pelo Governo do Estado.

Segundo os padrões tipológicos, a Santa Casa é constituída por conjunto de blocos, a maioria contendo um pavimento, porão alto e recuos frontais. A volumetria original está parcialmente preservada, apesar das adaptações feitas para a modernização das instalações hospitalares.

Cada bloco observa rigoroso padrão simétrico de formas e de composição dos vãos e elementos decorativos. Os blocos, distintos entre si, possuem jardins internos que implicam em separação uns dos outros, remetendo ao modelo hospitalar pavilhonar. Os blocos mais antigos são em estilo eclético, sendo a fachada da Maternidade em linhas clássicas.

A fachada principal possui frontão triangular com medalhão da Santa Casa, quatro pilastras com capitéis, frisos retos e três vãos de porta com bandeiras de arco pleno e platibanda reta que se estende por todo o bloco, contribuindo para a monumentalidade da edificação. Os vãos quadrados são dispostos

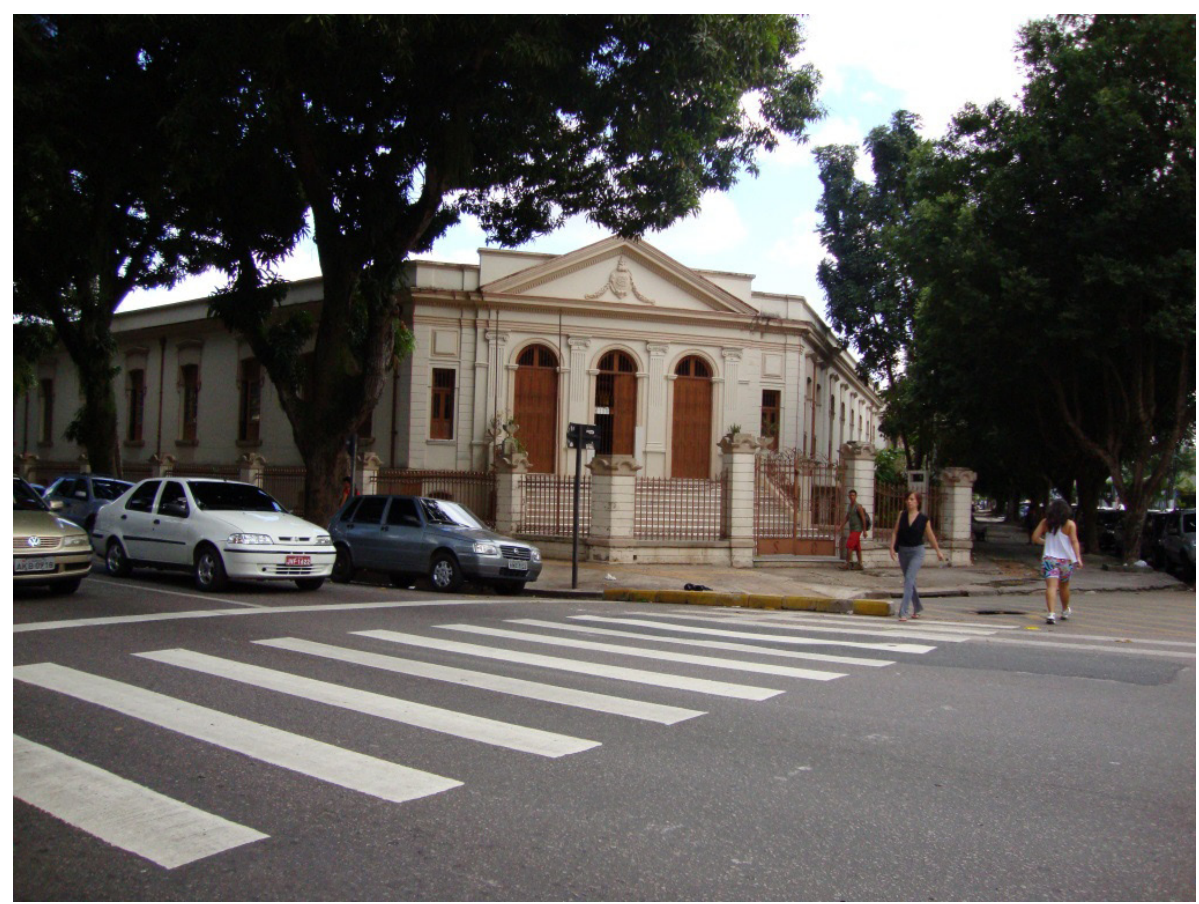

Figura 10 - Hospital da Santa Casa Maternidade. Foto: Carla Albuquerque (2009). 
de maneira harmoniosa e simétrica; as esquadrias são em madeira e vidro. A cobertura é formada por telha de barro composta por quatro águas em cada bloco.

Em 2008, denúncias de alto número de crianças mortas num curto período de tempo causou profunda crise na Instituição. Desde então, o Governo do Estado do Pará vêm realizando obras na Santa Casa, sem preocupação alguma com a preservação da riqueza patrimonial do prédio.

Em seu entorno, encontram-se boa parte dos hospitais que compõem o núcleo, a começar pela Faculdade de Medicina, que integra o Instituto de Ciências da Saúde da Universidade Federal do Pará (UFPA). A Faculdade de Medicina, cujo início data de 1919, foi a primeira a ser criada na Região Norte, atraindo alunos de estados vizinhos, já que as únicas instituições que ofereciam o curso no Brasil localizavam-se no Rio de Janeiro.

O Instituto de Ciência da Saúde da UFPA, conhecido simplesmente como Faculdade de Medicina, se localiza no bairro Umarizal, na Praça Camilo Salgado. É de propriedade da Universidade Federal do Pará, e começou a ser edificada em 1870, contando com a participação de diversos construtores.

Ao todo a instituição é formada por conjunto de blocos edificados independentemente de características arquitetônicas distintas. $\mathrm{O}$ prédio principal, o Palacete de Santa Luzia, adquirido em 1929, devido à proximidade ao Hospital da Santa Casa de Misericórdia, foi adaptado às exigências da formação em Medicina para servir como estabelecimento às aulas teóricas.

Caracterizado por arquitetura eclética, o imóvel foi edificado em três pavimentos, possuindo, originalmente, vãos com esquadrias de madeira; sacada de balcão com guarda-corpo avarandado e janelas com guarda-corpo entalado, ambos entalhados em ferro trabalhado; platibanda balaustrada com pináculos e porão baixo com óculos retangulares. A entrada principal situa-se na parte chanfrada da edificação, composta por três entradas com vergas em arco pleno e fachadas laterais simétricas (Figura 11).

A construção do Instituto de Anatomia Camilo Salgado em 1932 levou à modernização das instalações da Instituição, fato esse que culminou na remodelação da fachada do Palacete de Santa Luzia, no projeto arquitetônico de Augusto P. Lobão. Os detalhes arquitetônicos que embelezavam o imóvel foram removidos, sendo a atual fachada composta por linhas retas sem ornatos sinuosos (Miranda 2010).

A expansão pela vizinhança para ampliação das instalações físicas atinge a Avenida Generalíssimo Deodoro quando se constrói o Pavilhão Lauro Magalhães, edificado em dois pavimentos e inaugurado em $1^{\circ}$ de março de 1949. Seguindo o estilo arquitetônico do palacete, o pavilhão possui simetria na disposição de seus vãos, o predomínio pelo desenho de linhas retas representando a racionalidade na composição do imóvel.

A expansão não cessou, tanto que, em 


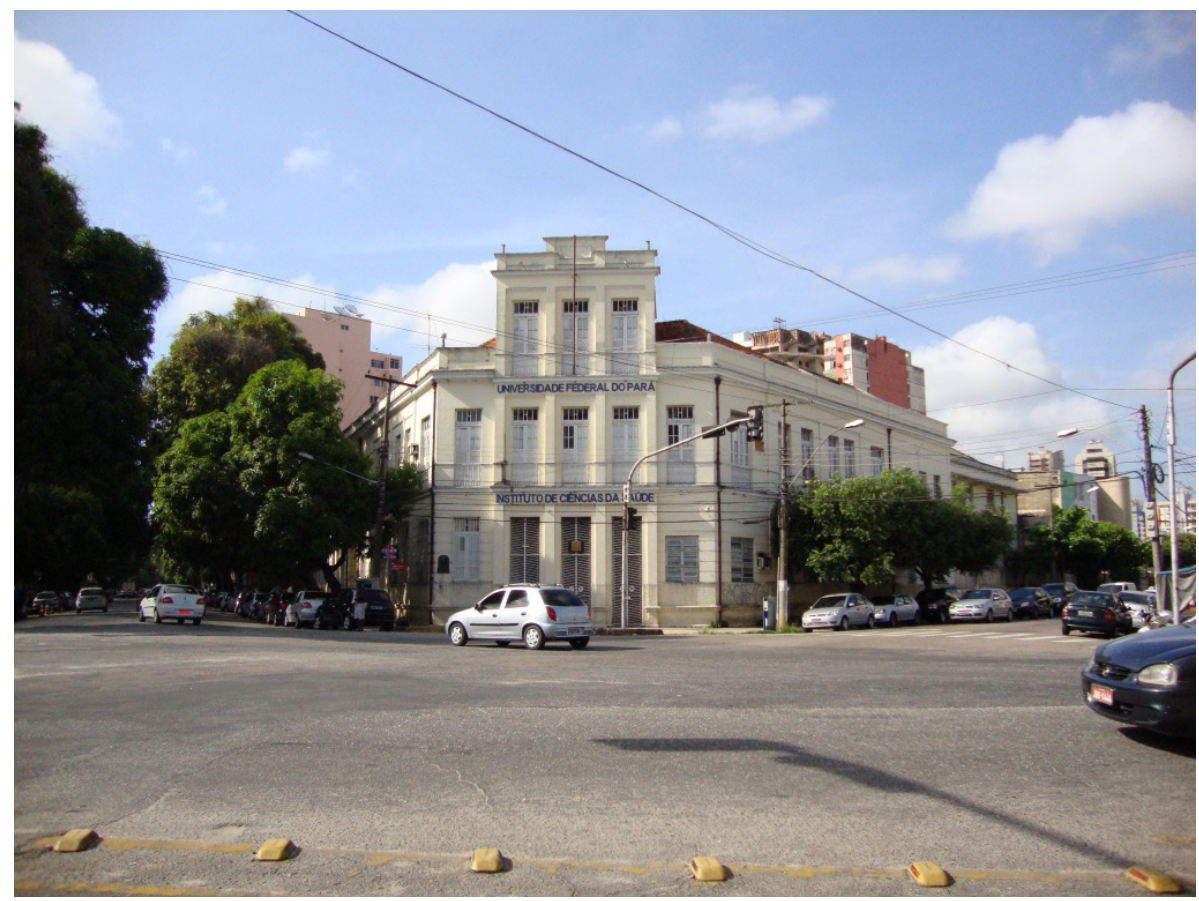

Figura 11 - Faculdade de Medicina da UFPA. Foto: Carla Albuquerque (2010).

1946, a Faculdade de Medicina criou o Instituto de Higiene integrado com Laboratório de Química Fisiológica e Fisiologia ao lado do Instituto de Anatomia Patológica. A particularidade do bloco é que, ao invés dele ter a entrada pela rua, foi idealizado para dentro do terreno do ICS, sendo preciso adentrar pelo Palacete de Santa Luzia. Entre o novo bloco e o palacete foi criado pátio interno aberto e bem arborizado, com chafariz e bancos, que proporciona ares de praça. O laboratório de Química, com linhas modernas, foi implantado no alinhamento do terreno frontal e lateral e edificado em dois pavimentos com cobertura em telha de fibrocimento. Hoje, o prédio abriga a Faculdade de Fisioterapia e Terapia Ocupacional.
Em 1949 foi construído o prédio do Biotério, edificado no interior do lote, construído em dois pavimentos em alvenaria de tijolo e com afastamento entre ele e os demais blocos. Hoje, o Biotério encontra-se desativado e o espaço dá lugar ao Serviço de Assistência Psicossocial (SAPS) aos discentes da UFPA e seus familiares. O prédio do Curso de Nutrição, também implantado no interior do lote, possui afastamento entre os demais blocos. Percebe-se, portanto, que o conjunto de edificações não é lido facilmente pelos que não frequentam o prédio quotidianamente.

Em terreno contíguo ao Instituto, na Avenida Generalíssimo Deodoro, encontrase o Núcleo de Medicina Tropical, antes Instituto de Higiene e Medicina Preventiva Dr. Olímpio da Silveira (1949-1969). 
Prédio de propriedade da Universidade Federal do Pará, sua construção foi realizada a partir de 1949, pela Construtora M. C. Macedo.

Devido às atividades realizadas pela Faculdade de Medicina e Cirurgia do Estado do Pará (FMCP) foi criado o Instituto de Higiene e Medicina Preventiva Dr. Olímpio da Silveira (IHMP), a partir da doação da prefeitura de quatro lotes contíguos à Faculdade, cuja obra foi concluída em 1954. Desvinculando-se da Faculdade de Medicina, quinze anos depois, passou a se chamar Núcleo de Patologia Regional e Higiene (NPRH) (Miranda 2010).

Em 22 de março de 1991, a Resolução $\mathrm{n}^{\circ} 576$ transformou o Núcleo de Patologia Regional e Higiene e fundou o Núcleo de Medicina Tropical (NMT). Caracterizado como edifício de três pavimentos, possui afastamentos lateral e frontal, volumetria retangular e aproximadamente $180 \mathrm{~m}^{2}$ de área construída, com cobertura em telha de fibrocimento sem calhas ou condutores pluviais.

$\mathrm{Na}$ fachada principal, seu acesso é feito por vãos de porta em estrutura de ferro e vidro transparente que compõem superfície de vidro que se estende do térreo ao segundo pavimento. Nos corpos laterais que configuram a fachada principal da edificação, as aberturas em colmeia de concreto são emolduradas, tendo como divisão painel vertical em concreto, e fechamento em vidro transparente, remetendo à linguagem do racionalismo italiano (Figura 12). Nas demais fachadas, não há elemento arquitetônico de destaque; essas são compostas por vãos verticalizados de portas e janelas em madeira, com venezianas e vidro, típicas da arquitetura belemense da primeira metade do século XX, que não dialogam com o modernismo explícito da fachada de acesso (Beltrão et al 2011).

No mesmo terreno ocupado pela Santa Casa, na Travessa 14 de Março, funciona o Hospital do Pronto Socorro Municipal, criado em meados da década de 1920, como forma de prestar atendimento de emergência aos pacientes que acorriam à Santa Casa (Beltrão et al 2011).

A necessidade de se criar um Serviço de Assistência Pública que prestasse cuidados médicos às pessoas mais necessitadas em caso de emergência levou à criação do serviço de assistência, que funcionou, inicialmente, como órgão auxiliar da Polícia e sob a dependência do Serviço Médico-Legal. Desvinculando-se dos mesmos, durante a intervenção federal de Magalhães Barata (1930-1954), foi transferido para prédio próprio, em frente ao Hospital da Ordem Terceira de São Francisco da Penitência, atendendo à população de maneira satisfatória (Meira 1986).

Em 1946, a falta de recursos para adquirir novos equipamentos e realizar reformas acarretou a transferência de suas atividades para o prédio onde funcionava o Instituto Evandro Chagas, localizado na Travessa 14 de março. No local foi construída a sede atual, cuja inauguração aconteceu em 2 de junho de 1950.

A Instituição é composta de quatro blocos de alvenaria, sendo um deles 


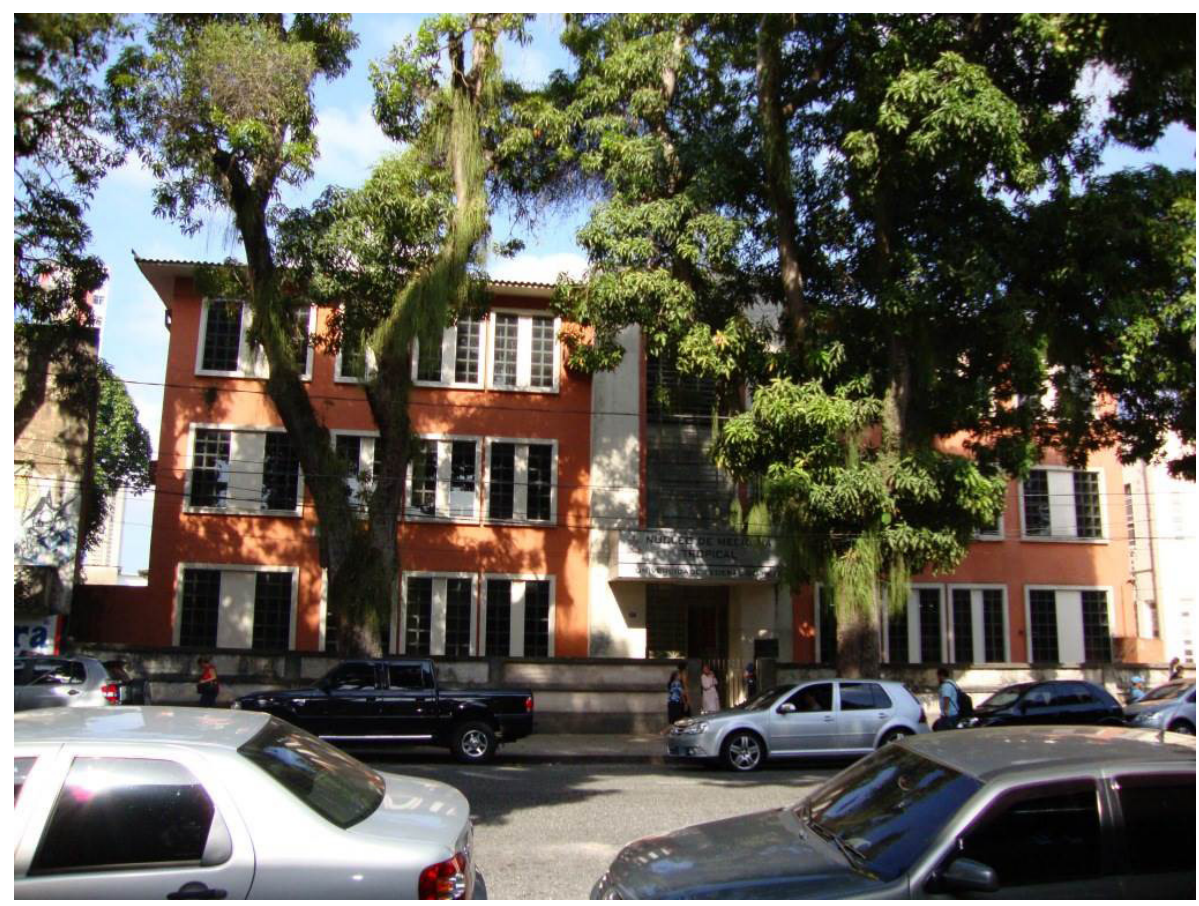

Figura 12 - Fachada Núcleo de Medicina Tropical. Foto: Carla Albuquerque (2010).

de construção recente, inaugurado em 2010, composto de quatro pavimentos. Caracteriza-se como edificação sem recuos frontais e laterais em relação ao terreno, e com ajardinamento escasso. A sua volumetria é em estilo moderno, de fachada assimétrica e aberturas de formatos variados. As esquadrias são, em sua maior parte, de alumínio. O revestimento externo é feito de pintura em cores claras e neutras, e internamente pode-se observar o mesmo padrão cromático. Há também variações de piso, sendo alguns em lajota cerâmica e outros em granilite nas cores cinza e vermelha (Beltrão et al 2011).

O Hospital Geral de Belém encontrase próximo à Santa Casa, no caminho da Rua Jerônimo Pimentel, em frente à Praça Santos Dummont (antiga Praça
Brasil). É mantido pelas Forças Armadas e, embora seja um Hospital do Exército, também atende civis, separados dos militares (estes classificados por hierarquia dentro do hospital). Oferece assistência médica e odontológica a militares e dependentes no Estado do Pará e no Maranhão (Beltrão et al 2011).

Funcionou em diversos locais antes de assumir o atual endereço, do Presídio São José a Manaus, no Amazonas em 1904, retornando a Belém 15 anos mais tarde, ocupando prédio no Largo da Sé (onde já funcionava antes da mudança). Em 1934, iniciam-se as obras da sede que ocupa atualmente, com a conclusão e inauguração das novas instalações em 1939. A denominação atual, Hospital Geral de Belém 
(HGeBe), foi recebida em 1953.

O hospital atende a civis e militares, tendo como finalidade básica, a assistência médica e odontológica a militares e seus dependentes de várias cidades do Pará e Maranhão; as emergências que chegam ao Hospital são atendidas e, caso necessário, encaminhadas para outras instituições.

O entorno do prédio se caracteriza por edifícios residenciais e pequena concentração comercial, com calçadas arborizadas ao redor da quadra ocupada pelo HGeBe. Sua fachada de linhas retas faz referência ao Art Decò no corpo central, arrematado por platibanda. Os seis pavilhões interligados seguem composição homogênea, com telhados em quatro águas recobertos por telhas de barro tipo francesa e vãos em verga reta. Apenas o pavilhão da frente faz parte do projeto original (Figura 13).

Internamente, no prédio principal, é possível observar algumas intervenções recentes quanto ao acabamento de pisos e pinturas. Os demais pavilhões, construídos posteriormente, seguem o estilo do prédio principal, diferenciando-se apenas pelo seu interior, com revestimentos mais ou menos recentes.

Pouco mais distante, mas ainda na Avenida Generalíssimo Deodoro (via que serve como elo entre os componentes deste núcleo), avista-se o Hospital Dom Luiz I, da Beneficente Portuguesa, idealizada pela Colônia Portuguesa no Pará.

Primeiro localizado num prédio próximo à Praça da República, próximo ao Café Chic e vizinho ao antigo Hotel da Paz, inaugurou-se em 1867, conhe- cido como Asilo Português da Infância Desvalida. Porém, mostrando-se insuficiente para atender à demanda, foi instalada, provisoriamente, uma enfermaria de dois pavimentos localizada na Rua Santo Antônio, conhecida como Casa de Saúde da Real Sociedade Portuguesa Beneficente. Até que, em maio de 1873, é levantada a proposta de compra de um dos dois lotes situados na Estrada Dois de Dezembro (atual Avenida Generalíssimo Deodoro) (Vianna 1974).

Acatada a aquisição do terreno pela Diretoria, contrata-se o arquiteto Frederico José Branco, idealizador do projeto que atende às exigências de higiene $\mathrm{e}$ saúde da época: edifício amplo, com boa insolação e luminosidade, bastante ventilado e arejado.

Em 1877 inaugura-se o Hospital Dom Luiz I, possuindo 253 leitos divididos em três setores: masculino, feminino e maternidade. Seus andares térreo e superior são destinados aos quartos individuais e serviços cirúrgicos; nos porões habitáveis encontram-se enfermarias, consultórios e serviços de apoio diagnóstico. O estabelecimento de saúde ocupa a totalidade do quarteirão em que se situa, com pavilhões no alinhamento lateral esquerdo e de fundo; e o bloco principal recuado frontalmente.

A fachada principal possui características neoclássicas como a simetria da edificação, vãos ornados com frontões triangulares e circulares, o frontão curvo que arremata o corpo central da fachada principal e platibanda que percorre toda a extensão do prédio. Os vãos alternam vergas retas, curvas em 


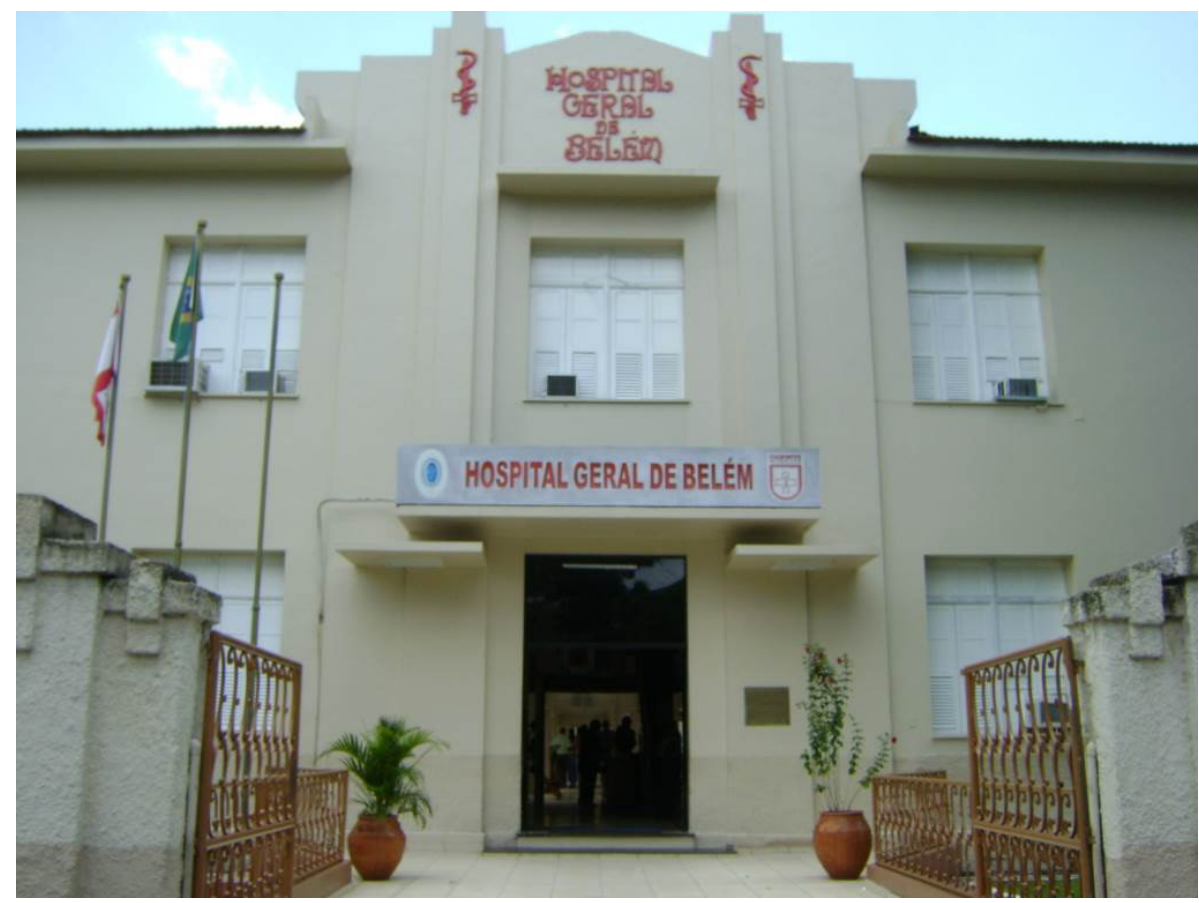

Figura 13 - Entrada principal do Hospital Geral do Exército. Foto: Laura Costa (2009).

arco pleno e ogival, demonstrando a assimilação de influências ecléticas. As pilastras apresentam-se na extensão da fachada como elemento de marcação e identificação do rigor das proporções. A cobertura original em telha de barro composta por três águas em cada pavilhão foi totalmente substituída pela telha do tipo fibrocimento (Figura 14) (Beltrão et al 2011).

A edificação apresenta conservação boa, porém percebe-se descuido com questões referentes ao lixo e à poluição do ambiente; ainda que as sucessivas ocupações dos afastamentos laterais e de fundos tenham prejudicado significativamente a ideia de modelo higienista.

A Clínica dos Acidentados encerra o trajeto que compreende o Núcleo da
Santa Casa. Obra dos irmãos Humberto Maradei Pereira e João Alberto Maradei Cardoso, que se iniciaram na Medicina através da ortopedia, a pequena clínica encontrava-se na Rua 13 de Maio, no Comércio. O empreendimento decorreu da necessidade de atendimento à traumatologia e ortopedia, especialidades não supridas de forma satisfatória pelo Pronto Socorro Municipal e que até hoje são as especialidades da instituição, cuja maioria dos atendimentos (em torno de 80\%) provém do SUS. A Clínica dos Acidentados, também conhecida como Clínica de Cirurgia Ortopédica Ltda, localiza-se no bairro de Nazaré na Avenida Nazaré.

Com o crescimento da demanda de atendimento de pessoas politraumatizadas, 


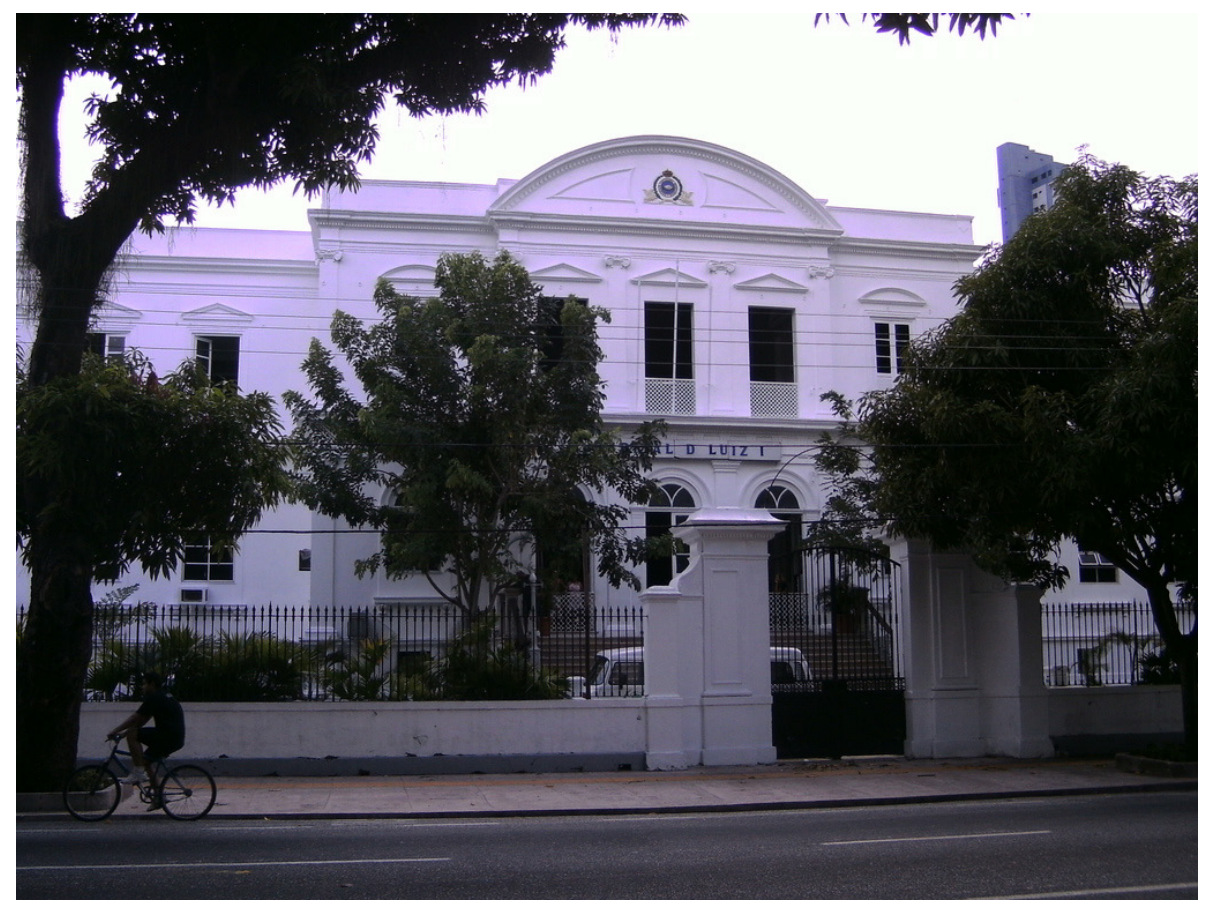

Figura 14 - Fachada Hospital D Luiz I. Foto: Carla Albuquerque (2009).

os Irmãos Maradei, com a ajuda do Governo Estadual, inauguraram em 1966 o espaço onde, ainda hoje, funciona a Clínica dos Acidentados em frente à Praça Santuário de Nazaré. O imóvel ocupado pela Clínica era antiga residência imperial de porão alto, de modo que a edificação precisou ser adaptada para responder aos padrões referentes de uma casa de saúde.

Mais tarde, em razão da crescente demanda, os irmãos Maradei investiram na compra de espaço contíguo à Clínica (antigo Colégio Líder), no propósito de ampliar as instalações físicas; ali foram realizadas as construções do bloco cirúrgico e mais 12 leitos para atendimento de urgência e emergência, oferecendo ao público 20 leitos. A condução da Clínica e o crescimento das atividades levaram à compra de outro terreno vizinho à Clínica; as ampliações permitiram a construção de um prédio de nove pavimentos com área construída de $6.103,89 \mathrm{~m}^{2}$.

Localizado numa área bem arborizada, o prédio de afastamento frontal e de fundo e recuo lateral esquerdo possui a fachada com acabamento em placa de granito preto e letreiros em aço inoxidável. Os seus vãos se mostram dispostos de forma simétrica, similares uns aos outros, usando os mesmos materiais: esquadrias em alumínio com fechamento em vidro transparente liso e com película translúcida para evitar o excesso de luminosidade nas enfermarias e apartamentos. Estes vãos, de dimensões elevadas, auxiliam na ventilação, na insolação e na salubridade adequada dos espaços hospitalares (Beltrão et al 2011). 


\section{O NÚCLEO DE EXPANSÃO}

O surgimento das instituições voltadas à saúde no chamado núcleo suburbano e de expansão só foi possível graças às intervenções que eliminaram as barreiras naturais impostas por áreas alagadas em Belém, que impediam a ampliação da cidade para o interior. Além disso, o pensamento higienista praticado pelo poder público, principalmente durante a intendência de Antonio Lemos, tinha por objetivo o embelezamento de Belém através de melhorias na infraestrutura, abertura de grandes avenidas e criação de praças e áreas verdes, mas também a construção de instituições hospitalares e de assistência à saúde pública em áreas afastadas, "setorizando" os enfermos para que não ficassem às vistas da sociedade.

O primeiro a compor o núcleo foi o Hospício de Lázaros do Tucunduba, fundado em 1814 e localizado na Rua Barão de Igarapé-Miri, no bairro do Guamá. O terreno, onde anteriormente funcionava uma olaria pertencente aos padres mercedários, foi adquirido pela Santa Casa de Misericórdia do Pará em 1807 para "recolher e afastar do convívio da sociedade os leprosos que vagavam pelas ruas de Belém" (Costa 2006: 98). As instalações do hospital eram precárias e a condição dos enfermos ficou mais crítica quando lá foi montada uma enfermaria para variolosos, visto que o Hospital da Santa Casa estava em condições impróprias para acolhê-los e, pelo fato de ser uma epidemia, a solução encontrada foi isolálos do núcleo urbano. Além dos enfermos acometidos pela varíola, também foram para lá pessoas com febre amarela e doentes mentais.

A enfermaria foi extinta em 1870, em função da queda no número de casos da epidemia, cujas vítimas foram transferidas para o Hospital da Caridade. Alguns anos mais tarde, em 1905, teve início sua reforma mais importante, provendo ao local energia elétrica, escolas elementares, espaço para jogos e uma capela. Quanto ao tratamento dos hansenianos, a preocupação com o contágio era tal que a Santa Casa mandou cunhar moedas para uso exclusivo desses enfermos. O local foi desativado em 1938, mas as demais colônias responsáveis pelo tratamento dos lázaros permaneceram em atividade até a década de 1970, quando a atenção e tratamento de hansenianos deixou de preconizar a segregação (Beltrão et al 2011).

A configuração espacial da colônia caracterizava-se pela regularidade na ocupação dos espaços, tendo como limites duas fileiras paralelas de habitações, que envolviam as duas enfermarias principais; a mais antiga, destinada aos pacientes do sexo feminino, que possuía em sua estrutura um amplo alpendre e capela, e duas outras enfermarias para pacientes do sexo masculino (Ramos 1997).

Próximo dali, o Hospital Universitário João de Barros Barreto surgiu dos resquícios do "Domingos Freire", hospital de isolamento que abrigava doentes acometidos por doenças epidêmicas no século XIX, como a febre amarela. Embora a distância da cidade fosse favorável, o acesso ao local era difícil, e o trajeto era vencido apenas a pé ou a cavalo. 
O Hospital Universitário Barros Barreto, localizado no bairro do Guamá, na Rua dos Mundurucus, teve sua construção iniciada a partir de 1940, pelo Departamento Nacional de Saúde. Suas obras foram interrompidas em 1942, e apesar da urgência da obra, - dado os altos índices de contágio e mortalidade por tuberculose no estado neste período -, as obras foram retomadas apenas em 1950. Desde sua inauguração, em 1959, o Hospital Barros Barreto vem realizando o tratamento de doenças infecto-contagiosas como a própria tuberculose, fato que ainda causa temor em alguns belemenses por medo do contágio e pelas tristes histórias vividas na instituição hospitalar (Figura 15).

O 'Barros Barreto' carrega consigo, até hoje, o estigma de ser contagioso e perigoso devido à relação do hospital com a tuberculose e outras doenças estigmatizadas, como HIV/AIDS, cólera, meningite, entre outras. Sua localização no bairro do Guamá - na época da construção caracterizado como área afastada -, se deve à política de segregação de doentes de tuberculose em lugares considerados aprazíveis e arborizados, condições que auxiliariam na recuperação. Além, também, da busca por locais pouco acessíveis para não permitir a proliferação do "mal do século" XIX no centro da cidade (Beltrão 2004). Em 1990 houve a transição da administração do Ministério da Saúde para a Universidade Federal do Pará (UFPA).

Seguindo os princípios de tratamento à tuberculose na época, o espaço se caracterizava por jardins cuidadosamente plantados, além da amplitude de corredores e enfermarias. Apesar da pressão pela construção de mais leitos, ainda busca-se a preservação das linhas originais do prédio, procurando atender às propostas de modernização e ampliação, mas sem comprometer o que construiu e consolidou.

No que se refere à sua arquitetura, o 'Barros Barreto' é um prédio sem ornamentos estilísticos, com linhas sinuosas presentes na fachada e ao longo da estrutura que lhe conferem formato moderno e audacioso para a época de seu projeto, década de 1930. O formato em $\mathrm{H}$ da planta permite a setorização dos serviços e das especialidades médicas, além de conferir à fachada dinamismo visual. Em virtude das diversas reformas que sofreu, seu interior é heterogêneo, o que produz conflito visual com o aspecto formal do restante da edificação (Beltrão et al 2011).

O Hospital Ophir Loyola, localizado no bairro São Brás, à Avenida Magalhães Barata, surge com o objetivo de lutar contra a infância desassistida e, mais tarde, contra o câncer. Foi inaugurado em 6 de outubro de 1912, por influência do Dr. Ophir Pinto Loyola, o denominado Instituto de Proteção e Assistência à Infância do Pará, em razão da falta de higiene e desnutrição, reflexo da condição de miséria social, para assim, minimizar a demanda de pacientes da Santa Casa (Martins 2006).

A primeira sede do Instituto funcionou na Rua Lauro Sodré (atual Rua Ó de Almeida) entre Rua Frei Gil de Vila Nova e Avenida 15 de Agosto (Avenida Presidente Vargas). Depois se mudou para a Rua 13 de Maio, 104 entre Travessa 7 de Setembro e Ave- 


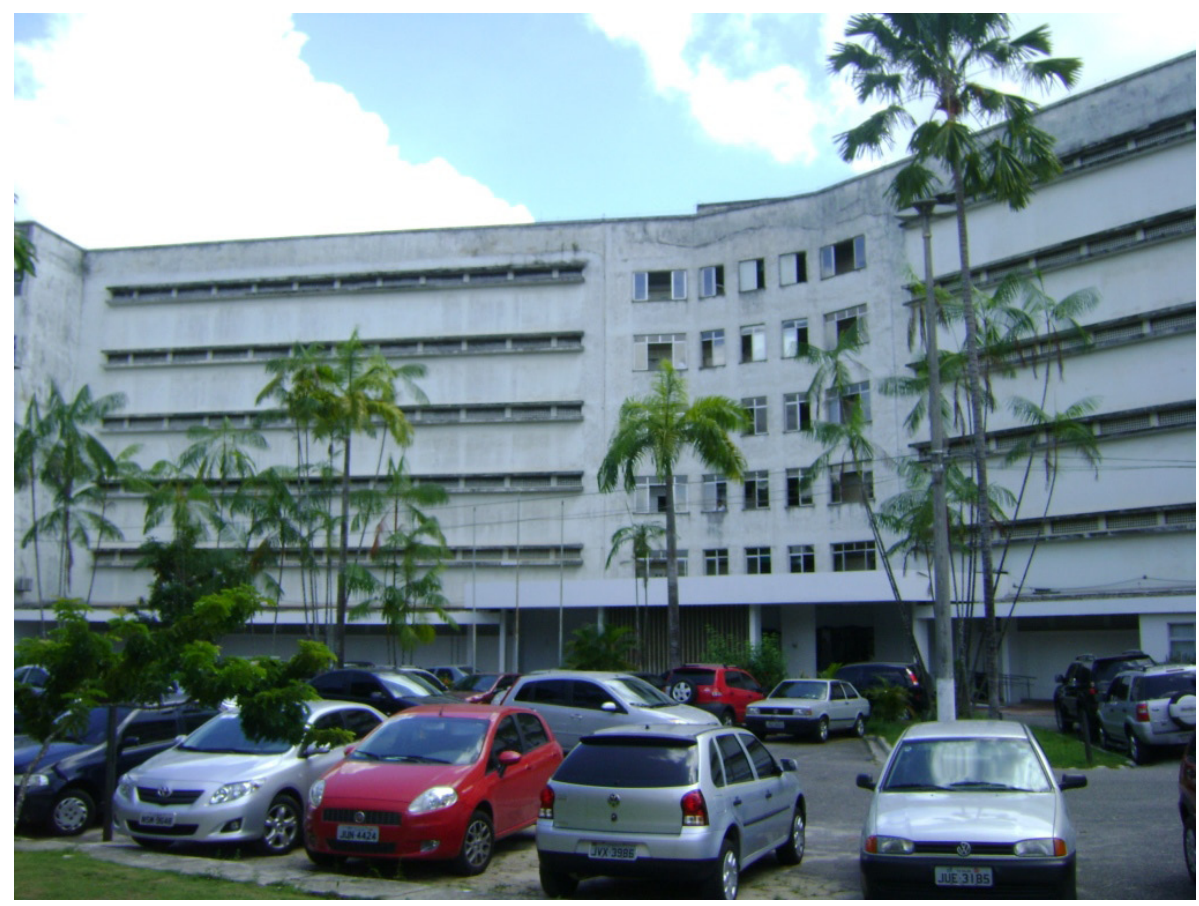

Figura 15 - Hospital Barros Barreto. Foto: Laura Costa (2009).

nida Portugal, em imóvel pertencente à Santa Casa. Em 1932, transferiu-se para outra sede mais ampla na esquina da Avenida Nazaré com a Travessa Joaquim Nabuco.

Um ano depois, foi oferecido como pagamento para quitação da dívida do Estado um terreno localizado na então Avenida Independência, de amplo espaço para o hospital exercer suas atividades, vindo a ser inaugurado em 19 de abril de 1941, com a denominação Instituto Ophir Loyola.

Em 2006, a Lei Estadual nº 6.826 cria o Hospital Ophir Loyola, órgão de atuação especial da Secretaria de Estado de Saúde Pública, destacando-se na região Norte como o único hospital de referência em tratamento de câncer.
O imóvel é localizado em uma das principais avenidas de escoamento do trânsito na cidade, de intenso tráfego e bem arborizada por mangueiras centenárias. A área construída do Hospital é de aproximadamente $21.088,48 \mathrm{~m}^{2}$; constituída por pavilhões que foram acrescidos no decorrer de sua história e em função da ampliação das atividades hospitalares (Beltrão et al 2011).

O estabelecimento abriga blocos hospitalares que variam entre dois e sete pavimentos, seguindo o modelo monobloco. Nota-se a subsistência de padrões similares de dimensões, formas, materiais construtivos e de composição dos vãos. As esquadrias são em madeira e vidro, e alumínio e vidro. A cobertura é composta por quatro águas em telha de fibrocimento. O 
acesso ao hospital pode ser feito pela Avenida Magalhães Barata, entrada principal, e também pela Travessa 14 de Abril (Figura 16).

Com a aquisição de terrenos que serviriam para ampliação das instalações hospitalares, o HOL incorporou a edificação que abrigava a Residência Oficial do Vice-Governador do Estado, imóvel que foi preservado integralmente e aproveitado como Departamento de Ensino e Pesquisa da Instituição.

Seguindo pelo endereço do HOL em direção à saída de Belém, pela Avenida Almirante Barroso, encontra-se o primeiro prédio onde funcionou o Instituto Evandro Chagas, fundado em 1934. A característica da edificação principal reflete o uso como residência antes da ocupação institucional, assim como outras construções ao longo da antiga Estrada de Ferro Belém-Bragança.

O Instituto Evandro Chagas, localizado no bairro do Marco, se originou a partir de 1934, com a descoberta de 41 casos de leishmaniose visceral em localidades no interior do país. Isto acarretou a vinda do então diretor do Instituto Oswaldo Cruz, Evandro Chagas, ao Pará, o qual pôde realizar seu projeto de fundar o Instituto de Pesquisa Experimental do Norte (IPEN), em 11 de novembro de 1936, com o objetivo de estudar o calazar e outras doenças regionais - malária, leishmaniose tegumentar, bouba, filariose e as verminoses intestinais (Deane 1986).

Em 1940, com o falecimento de Evandro Chagas, o Instituto passa a receber a denominação de "Instituto Evandro
Chagas". Dois anos depois, o Serviço Especial de Saúde Pública (SESP) o incorpora como seu laboratório central e órgão de pesquisa.

Em 22 de maio de 1970, o IEC foi transferido do âmbito da FSESP para a Fundação Oswaldo Cruz (FIOCRUZ), voltando a ser reintegrado à FSESP cinco anos depois, ficando subordinado diretamente à Presidência até 1990, como organismo de pesquisas biomédicas. Em 1991, integrou a Fundação Nacional de Saúde, criada pela fusão da FSESP e da Superintendência de Campanhas de Saúde Pública (SUCAM). Apenas em 9 de junho de 2003 passou a integrar a estrutura da Secretaria de Vigilância em Saúde (SVS), como unidade gestora independente, na qual se encontra atualmente.

Sua arquitetura caracteriza-se por ser bastante singular, com influência das residências germânicas, cobertura achatada em suas extremidades e ornamentação peculiar. A escadaria que dá acesso à entrada principal é robusta, ligeiramente curva em suas extremidades e arrematada por pinhas laterais, fazendo jus ao estilo do prédio. O interior é todo em madeira de lei, e o prédio principal possui porão habitável onde anteriormente funcionavam vários serviços do IEC -, e dois pavimentos. A fachada do hospital tem simetria e ritmo equilibrado pela sequência de janelas e, acima, a cobertura de inclinação singular remete aos frontões triangulares clássicos (Figura 17).

Apesar de não ter sido tombado, o Instituto procura preservar o patrimônio, 


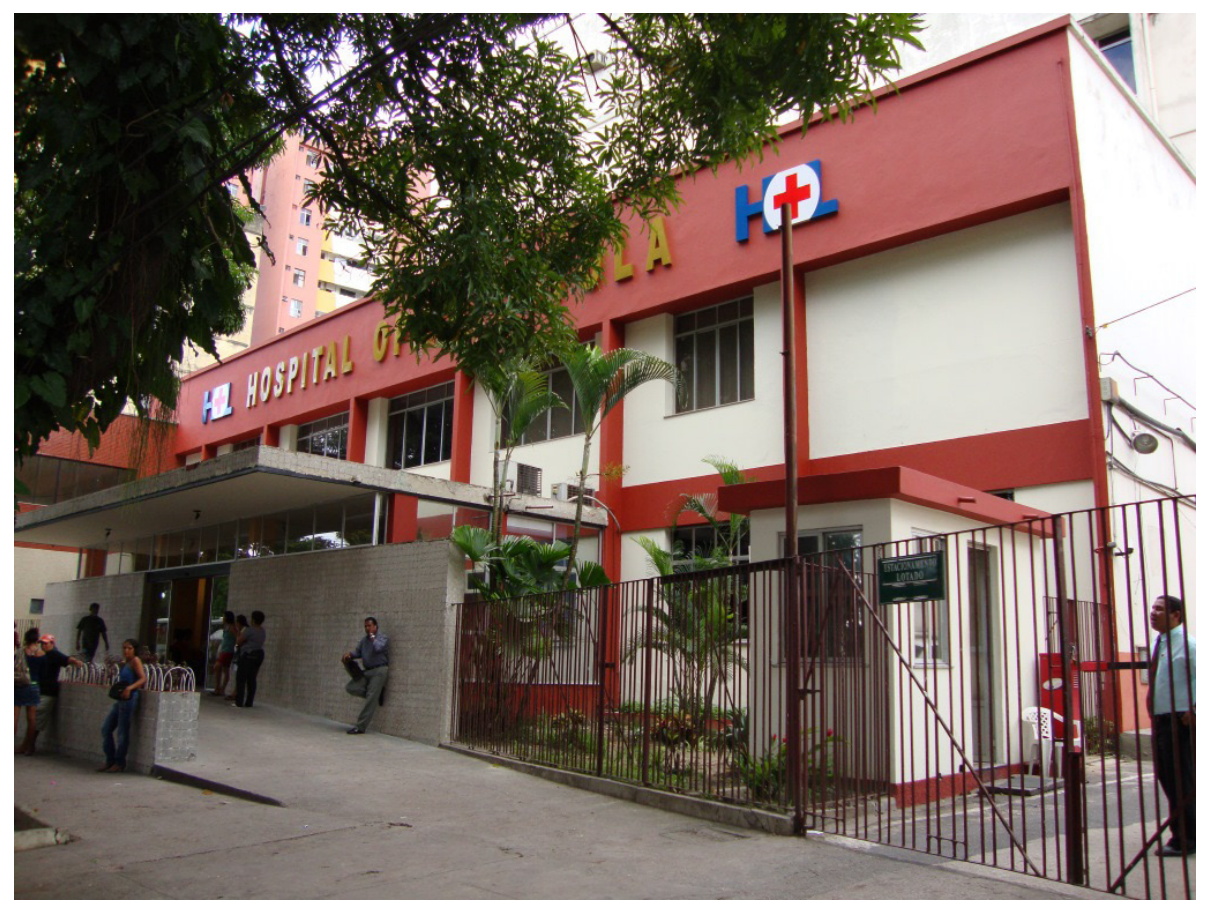

Figura 16 - Entrada principal HOL. Foto: Carla Albuquerque (2009).

por meio de reparos frequentes, valorizando as características arquitetônicas originais. Todavia, nota-se que a construção já recebeu alterações, como a construção de banheiros nos dois pisos e de um prédio acoplado aos fundos, com acesso feito por escada lateral.

O Hospital Psiquiátrico Juliano Moreira, também chamado Hospício dos Alienados, localizava-se no bairro do Marco, em frente ao monumento do Marco da Légua, na Avenida Almirante Barroso. $O$ terreno adquirido para construir o hospital, por sua localização, atendia às exigências da política higienista da época. Entretanto, a construção apresentou falhas construtivas, tornando necessários alguns reparos emergenciais antes de sua inauguração, marcada pela chegada de sete "loucos" do Hospício dos Lázaros.
Apesar dos reparos e manutenção constante do hospital, o então governador Augusto Montenegro (1901-1909) observou "condições tais que, longe de favorecer a cura, apresentavam o triste desfecho, pela intercorrência de mortos diversos", bem como a falta de equipamentos adequados para tratar os pacientes, tendo se tornado o hospício um "depósito de loucos" (Meira 1984:8). O governo anterior, de Paes de Carvalho (1897-1901), tinha intenção de transferir as instalações para outro local, mas Montenegro preferiu investir na melhoria do prédio. Demoliu a casa de banhos que causava infiltrações e era foco de polinevrite e construiu outras duas com modernos aparelhos hidroterápicos trazidos da Europa.

Apesar dos óbices impostos pela estru- 


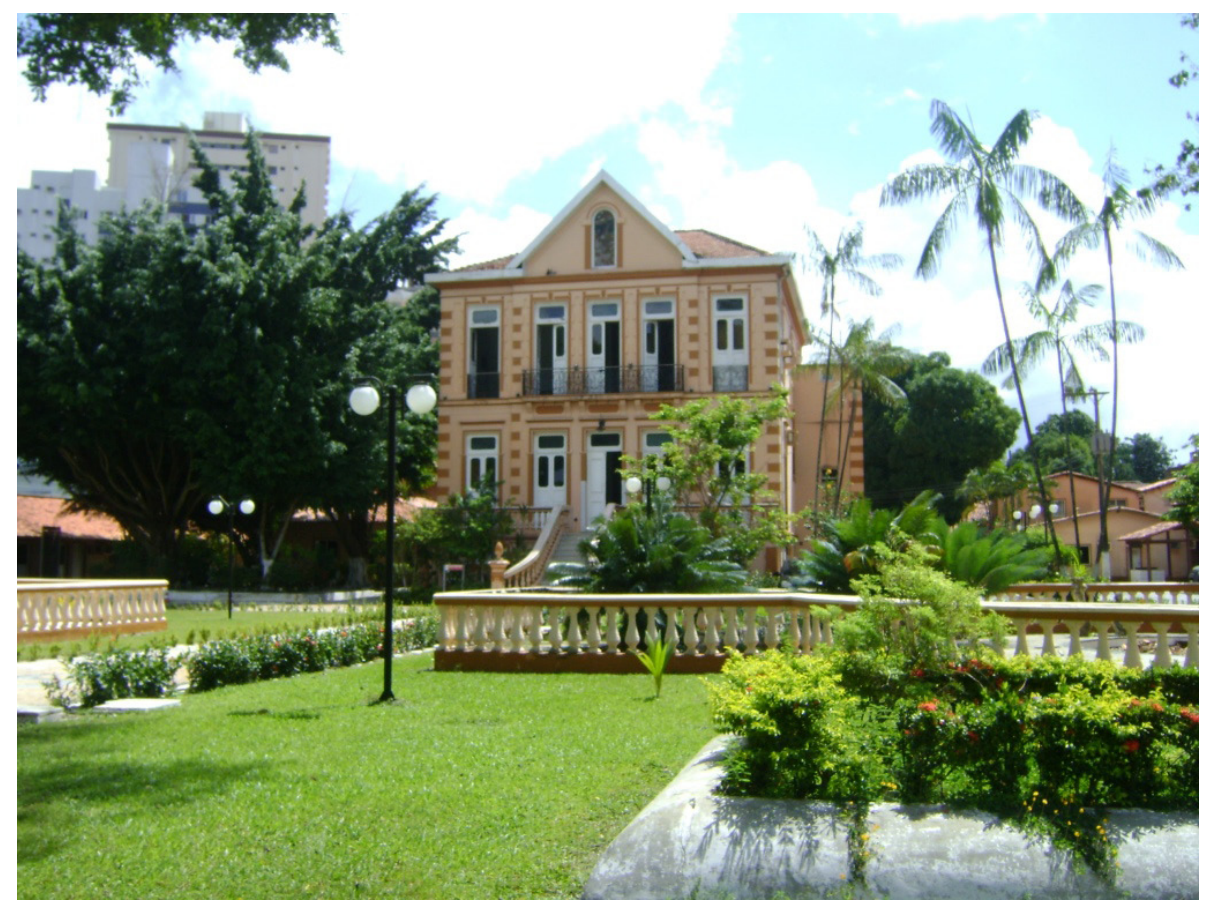

Figura 17 - Instituto Evandro Chagas. Foto: Laura Costa (2009).

tura física, registraram-se importantes avanços no tratamento psiquiátrico, que repercutiram na mudança do nome "Hospício de Alienados" para "Hospital Psiquiátrico Juliano Moreira", em 1937, homenageando o médico brasileiro responsável por utilizar métodos de vanguarda para assistir aos doentes mentais. Outras intervenções foram a abolição da camisa de força e o uso da praxiterapia, envolvendo atividades como pintura, escultura, bordado, danças e passeios. Contudo, a instituição passou gradualmente a ser relegada pelo governo e, após o misterioso incêndio que destruiu parte de suas instalações em 1982, teve suas atividades encerradas. O prédio original foi demolido em 1989, no espaço hoje funciona o Centro de Ciências Bi- ológicas da Universidade do Estado do Pará (UEPA).

Construído entre os anos de 1887 e 1892 , cujo projeto teve como autor o engenheiro Manoel Odorico Nina Ribeiro, destinou-se ao tratamento dos alienados, visto que o Asilo de Alienados do Tucunduba foi desativado. Em 1892, o hospital recebeu os doentes transferidos do antigo asilo. Em 1903, a administração do Hospício dos Alienados, até então à cargo da Santa Casa de Misericórdia, passou para a gestão do Estado.

O hospital era uma construção predominantemente horizontal, marcada pela simetria característica das construções de partido neoclássico, cujas aberturas organizavam-se em ritmo regular. Adotou o modelo pavilhonar, com 
setores específicos para homens, mulheres e crianças. A entrada principal da instituição, de frente para a Avenida Almirante Barroso era destacada pelo portão trabalhado em ferro, o qual dava acesso ao hall do prédio. $\mathrm{Na}$ fachada, observava-se o frontão triangular, pilastras com capitéis coríntios, posicionadas nas laterais do vão de acesso principal em formato de arco pleno, além do uso de cúpula encimada por uma lanterna (Figura 18) (Beltrão et al 2011).

Pela Avenida Almirante Barroso, é possível encontrar, além do terreno onde funcionou o Hospital Juliano Moreira, o Hospital da Aeronáutica de Belém (HABE), inaugurado em plena Era Vargas, no ano de 1944, resultado da necessidade de criar uma base aérea de apoio aos Aliados na cidade. Ao fim da guerra, correu o risco de ser substituído por um centro de abastecimento de material sanitário, mas sob protestos do brigadeiro Eduardo Gomes, que sugeriu a mudança para uma $\mathrm{Ma}$ ternidade da Legião Brasileira de Assistência, o hospital foi preservado. De acordo com Beltrão et al (2011),

O HABE é classificado como Hospital de Área de $3^{\circ}$ escalão do Sistema de Saúde da Aeronáutica (SISAU), com a principal função de oferecer assistência médico-hospitalar aos militares da Aeronáutica e seus dependentes, além de atividades no campo da medicina preventiva, ensino e perícia médica.

As instalações hospitalares atendiam às demandas da $1^{\text {a }}$ Zona Aérea lá instalada, hoje Primeiro Comando Aéreo
Regional (I COMAR). Em 1998, já dispunha de 80 leitos, dos quais, 20\% eram destinados a pacientes conveniados ao Sistema Único de Saúde (SUS); e tinha como principal função a assistência médico-hospitalar aos militares da Aeronáutica e seus dependentes além de atividades no campo da medicina preventiva, ensino e perícia médica. ${ }^{7}$

Suas características arquitetônicas obedecem à rigidez do estilo militar, com pavilhões - onde são setorizados os serviços médicos -, sem ornamentos e com cobertura em fibrocimento. A exceção é apenas de um prédio destinado ao tratamento odontológico, que apresenta características modernas. Logo na entrada é possível ver o Pronto-Socorro e, próximo a este, está localizada a capela mortuária em homenagem à Nossa Senhora de Loreto, padroeira da Aeronáutica.

Ao longo do terreno há também prédios em que funcionam a Direção e a Casa do Diretor, sendo a sede administrativa um chalé em estilo eclético, construído no início do século XX (1904), na Era da Borracha, de elegantes escadarias de ferro rendado, símbolos de riqueza e status. Formado originalmente por três pavimentos, teve o pavimento superior removido na década de 1970; apresenta cobertura em duas águas, porão com 2, 85 metros de altura e primeiro pavimento com pé direito de 3,5 metros, além do uso de gradis e balaustrada em ferro e colunas envolvendo a edificação, exibindo características clássicas grecoromanas (Figura 19)(Feitosa et al 2009).

A casa destinada à residência do dire- 


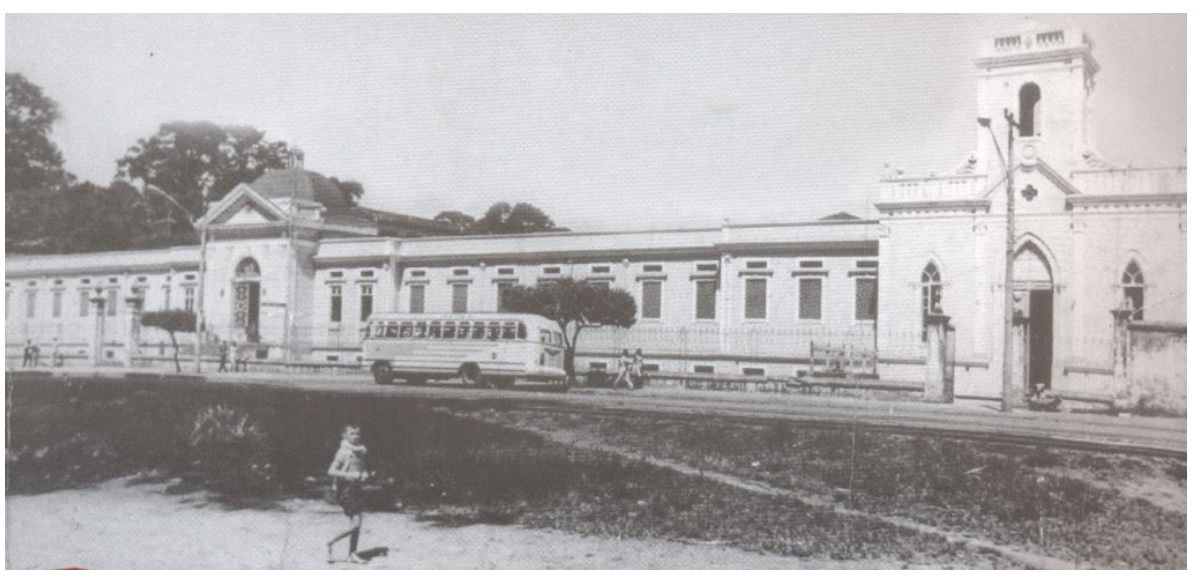

Figura 18 - Hospital Juliano Moreira. Fonte: Ricci \& Valentim (2009: 26).

tor também se apresenta no estilo dos palacetes europeus, com cobertura em telhas francesas, de cujas laterais sobressaem-se torres oitavadas de influência germânica, enquanto que a capela votiva ocupa um antigo bangalô da primeira metade do século XX, também adaptado.

Por fim, o Hospital de Clínicas Gaspar Vianna (HCGV) é o mais recente a compor o núcleo de expansão, tendo sido criado em 1985, como resultado de um plano do Governo do Estado para implantar um Estabelecimento Assistencial de Saúde voltado para o atendimento da rede estadual, com clínicas básicas e de atendimento especializado em Psiquiatria. Em 1987, foi concluída a Clínica Psiquiátrica, o bloco de acesso e serviços externos e gerais, mas apenas dois anos depois os leitos foram disponibilizados para a população. Nesse período, a obra sofre paralisação, reiniciando em 1990.

Em 1991, ano do Centenário de Gaspar Vianna, a instituição recebeu o nome do médico e cientista paraense e começa a oferecer à população os serviços de Ambulatório. Em 1998, recebe financiamento do Projeto REFORSUS, o que ocasionou mudanças na estrutura física da instituição, ampliando seu atendimento para os serviços de Nefrologia, Cardiologia e Obstetrícia de Alto Risco.

O Hospital de Clínicas Gaspar Vianna, cujo projeto é de autoria da arquiteta Fátima Vianna, localiza-se no bairro da Pedreira, na Travessa Alferes Costa, s/n. O Hospital de Clínicas é uma construção em estilo moderno, com volumetria inserida no terreno de forma diagonal e fachada principal voltada para o Norte. Com afastamentos frontais e laterais, é dividido em oito blocos interligados, com áreas abertas que favorecem a ventilação, arborização e iluminação natural. A instituição conta com 13 blocos, sendo nove destinados às funções administrativas, clínicas e laboratório; nos demais localizam-se os serviços gerais e o departamento de engenharia. Em termos de planta, cada bloco tem uma configuração particular, contudo 


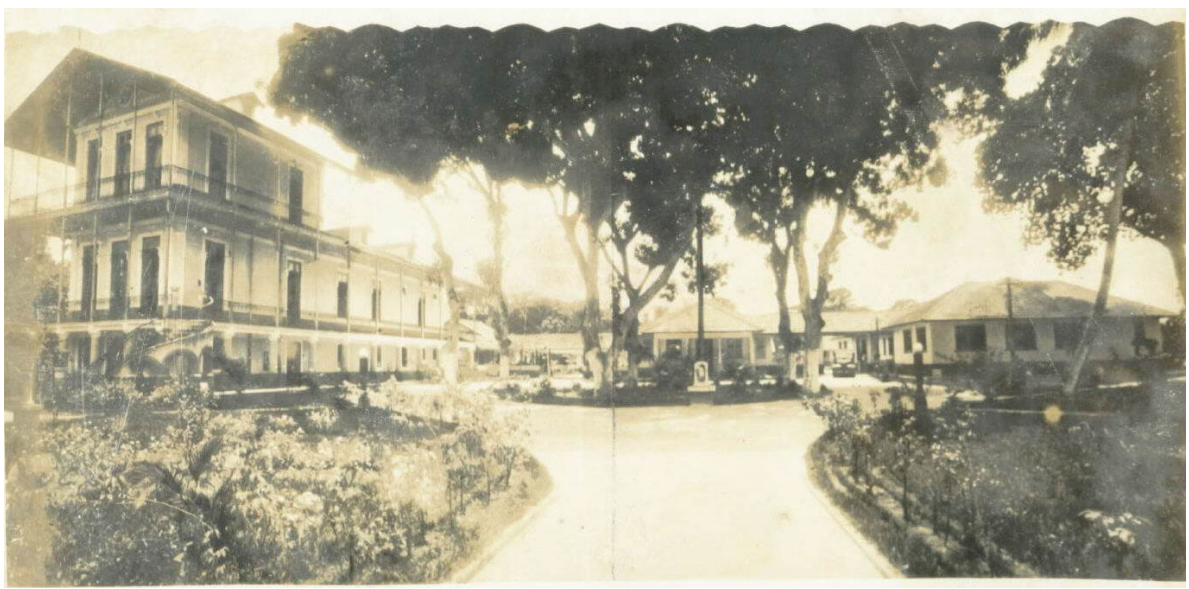

Figura 19 - HABE na sua inauguração. Fonte: Arquivo da unidade.

certos padrões são frequentes, como extensos corredores com hall central. Externamente, os acabamentos são em pintura lisa ou pastilhas de cerâmica (Beltrão et al 2011).

\section{PARA FINALIZAR...}

A construção da memória de um povo é parte da imagem que este tem de si e que quer expor para o outro. Os apagamentos impostos pelos poderes públicos direcionam a imagem da cidade de Belém que se tem hoje, e que será legada à posteridade: uma cidade com poucos marcos em que se apoiar, em que a modernidade avança de modo irregular, devastando o material existente, sem substituí-lo por algo de maior valor, pelo menos estético.

O incessante desejo que impele o anjo da história ao futuro, como narra Walter Benjamin (1985), impede recordar o passado, feito de ruínas. Esta cena de devastação, em cujo espelho se refletem seus habitantes, transforma e transtorna a configuração de sua personalidade, dilapidada, sem ao menos fragmentos aos quais poderia recorrer para montar um quebra-cabeças do tempo.

À Belém dos casarões invadidos pela natureza e das edificações ditas históricas é negado o reconhecimento de sua múltipla temporalidade, pela destruição dos traços antigos, pelo abandono, pelos acréscimos despudorados de concreto sem alma... Espera-se que esse trabalho venha trazer uma gota de inspiração para o conhecimento e valorização de nosso patrimônio, evocando através de relatos e imagens muitas possibilidades que foram perdidas, e muitas outras que ainda nos aguardam, espreitando num vão de porta ou numa esquadria mutilada, na existência muda de arcabouços desocupados, de edificações fantasmas, enquanto novas babilônias se erguem, alargando seus domínios. 


\section{NOTAS}

1 A Casa de Oswaldo Cruz/FIOCRUZ coordena, desde 2007, a Rede Brasil de Patrimônio Cultural da Saúde, tendo como responsáveis Paulo Roberto Elian dos Santos e Renato da Gama-Rosa Costa. A Rede Brasil tem como objetivo realizar o Inventário Nacional do Patrimônio Cultural da Saúde, por meio da ação cooperativa entre diversas instituições de ensino e pesquisa brasileiras. O resultado do Inventário realizado em Belém traduziu-se em 23 fichas, nas quais consta a síntese das informações históricas e arquitetônicas das instituições, disponíveis para consulta em: http:// patrimonioarquitetonico.coc.fiocruz.br/ cgi-bin/wxis.exe/iah/?IsisScript=iah/iah. xis\&lang $=\mathrm{E} \&$ base $=\mathrm{BARQ}$

${ }^{2}$ Amazônia Felsínea. 1999. Antonio José Landi: itinerário artístico e científico de um arquiteto bolonhês na Amazônia do século XVIII. Lisboa: Comissão Nacional para as Comemorações dos Descobrimentos Portugueses.

${ }^{3}$ Hospital Naval de Belém. Livro do Estabelecimento. [Belém: s.n., 19--] v. 1 e 2.

${ }^{4}$ Diário do Pará. Os 366 anos da Ordem Terceira. Belém, 12 dez. 1995. Caderno A, p. 04.

${ }^{5} \mathrm{O}$ ano dos 20 anos: uma trajetória comprometida com a qualidade de com a vida. Doação. HEMOPA. Belém, jun. 1998, p. 6-7, 1988.

${ }^{6}$ No local funcionam apenas atividades administrativas e laboratórios do referido Instituto, cuja sede foi transferida para o município de Ananindeua, PA.

${ }^{7}$ HABE comemora 54 anos. O Liberal. Belém, 10 jan. 1998: p. 7.

\section{REFERÊNCIAS}

Baena, A. L. M. 2004 [1833]. Ensaio corográfico sobre a Província do Pará. Brasília: Senado
Federal, Conselho Editorial.

Beltrão, J. F. 2004. Cólera, o flagelo da Belém do Grão-Pará. Belém, EdUFPA/MPEG.

Beltrão, J.F., C.S.Miranda, M. C. Henrique, L. C. C. Costa, C.F.R. Albuquerque. 2011. Inventário Nacional do Patrimônio Cultural da Saúde: Bens Edificados e Acervos - Patrimônio del em Saúde em Belém-Pará. Relatório final de pesquisa. Belém: Universidade Federal do Pará - Instituto de Filosofia e Ciências Humanas/ Faculdade de Arquitetura e Urbanismo; Rio de Janeiro: Fundação Oswaldo Cruz. CDROM. Inédito.

Benjamin, W. 1985. Obras Escollidas. Magia e técnica, arte epolitica: ensaios sobre L iteratura e História da Cultura. vol. 1. São Paulo: Brasiliense.

Brasil. Ministério da Saúde. Secretaria de Gestão Estratégica e Participativa. 2006. A construção do SUS: histórias da Reforma Sanitária e do Processo Participativo. Ministério da Saúde, Secretaria de Gestão Estratégica e Participativa. - Brasilia: Ministério da Saúde.

Costa, M.N.P. 2006. Caridade e Saúde Pública em Tempos de Epidemias - Belém 1850-1890. Dissertação de Mestrado. Programa da Pós-Graduação em História, Centro de Filosofia e Ciências Humanas, Universidade Federal do Pará, Belém.

Deane, L.M. E. 1986. Histórico do Instituto Evandro Chagas - Período 1936-1949, in Instituto Evandro Chagas: 50 anos de contribuição às ciências biológicas e à medicina tropical. Belém: Fundação Serviços de Saúde Pública.

Feitosa, A., F. Garcia, T. Parente. 2009. Histórico e Levantamento do Hospital da Aeronáutica - Chalé da Administração. Trabalho Final da Disciplina Restauro, elaborado sob orientação da Professora Ana Lea Nassar Matos. Faculdade de Arquitetura e Urbanismo. Belém: Universidade Federal do Pará. Inédito.

Martins, M.R.M. 2006. Instituto de Proteção e 
Assistência à Infância do Pará: Instituto Ophir Loyola. Belém.

Meira, C. 1984. O Hospício dos Alienados. O Liberal, 25 mar.: p. 8. Belém. 1986. Medicina de outrora no Pará. Belém: Editora Grafisa.

Miranda, A.G. 2010. Memória bistórica da Faculdade de Medicina e Cirurgia: da Fundação à Federalização. Belém - PA. Gráfica da UFPA.

Ramos, J. M. T. 1997. As memórias do hospício dos lázaros do Tucunduba. Monografia de Graduação. Departamento de História, Universidade Federal do Pará, Belém. INédito,

Ricci, M. \& R. Valentim (orgs.). 2009. História, loucura e memória: $O$ acervo do Hospital Psiquiátrico "Juliano Moreira". Belém: Secretaria de Estado de Cultura/ Arquivo Público do Estado do Pará.

Secult. Secretaria Executiva de Cultura do Estado. 2006. Feliz Lusitânia/Forte do Presépio - Casa das Onze Janelas, Casario da Rua Padre Champagnat. Belém, SECULT.

Vianna, A. 1974. A História da Benemérita Sociedade Portuguesa Beneficente. Belém, sem editora.

1992 [1902]. A Santa Casa da Misericórdia Paraense. Notícia Histórica (1650-1902). Coleção Lendo o Pará, Belém: SECULT.

Recebido em 30/05/2013.

Aprovado em 31/07/2013. 